\title{
Ecuador y su obstinación monetaria: causas de la dilatada vigencia del patrón de cambio oro
}

\section{Ecuador and its Monetary Obstinacy: Causes of the Prolonged Validity of the Gold Exchange Standard}

\author{
Gonzalo J. Paredes \\ Universidad de Guayaquil, Guayaquil, Ecuador, \\ email: gonzalo.paredesr@ug.edu.ec
}

\begin{abstract}
Resumen. El objetivo de este artículo es establecer las razones que tuvieron las autoridades económicas del Ecuador en permanecer dentro del bloque del patrón oro, a pesar de que los países sudamericanos y Gran Bretaña (país que impulsó el patrón cambio oro en Europa y en el resto del mundo) lo habían abandonado. La investigación se basa en dos procesos: el heurístico y el hermenéutico. Se concluye que la obstinación monetaria se origina por la influencia e insistencia del presidente de la misión de expertos financieros, Edwin Walter Kemmerer; por la vigencia del patrón de cambio oro en Estados Unidos; por los fundamentos del propio sistema monetario, y por los fantasmas del pasado, es decir, los intereses económicos y financieros de la banca privada.
\end{abstract}

Palabras clave: patrón oro; deflación; régimen monetario.

Abstract. The aim of this study is to establish the reasons that the economic authorities of Ecuador had to remain in the block of the gold standard, despite the fact that South American countries and Great Britain (country that promoted gold standard in Europe and the rest of the world) had abandoned it. This research is based on two processes: heuristic and hermeneutic. Through this study, it is concluded that monetary obstinacy is due to the influence and insistence of the president of the financial experts mission, Edwin Walter Kemmerer; the validity of the gold standard in the United States; the foundations of the own monetary system; and, the "ghosts of the past": the economic and financial interests of private banking.

Key words: gold standard, deflation, monetary regime.

Fecha de recepción: 24 de abril de 2017. Fecha de aceptación: 22 de enero de 2018.

JEL: N16; E31; E42; E58

Am. Lat. Hist. Econ., may.-ago., 2018, pp. 106-145 | DOI: 10.18232/alhe.884 
Parte de esta investigación está subvencionada por la Universidad de Guayaquil con la cooperación y ayuda de la Universidad Católica de Santiago de Guayaquil.

\section{INTRODUCCIÓN}

ک os países en desarrollo muchas veces importaron instituciones para conseguir credibilidad y estabilidad social. Todavía es muy frecuente ese tipo de políticas. No obstante, el riesgo es alto, ya que esas instituciones chocan con las del país receptor. Ecuador, a diferencia de los demás países de América Latina, según Miño (2008), fue el último en salir del patrón de cambio oro. Lo abandonó el 8 de febrero de 1932. En 1927, un pequeño país de Sudamérica importó numerosas instituciones recomendadas por Edwin W. Kemmerer, profesor en la Universidad de Princeton. Durante la década de 1920 fueron muchos los países donde Kemmerer iba "predicando el evangelio del patrón oro y de la independencia del Banco Central" (Eichengreen, 2000, p. 69).

¿Por qué Ecuador y los funcionarios públicos de aquella época prefirieron recorrer el camino tortuoso de la deflación y la crisis social y política para mantener hasta las últimas consecuencias un régimen monetario tan rígido como era el patrón de cambio oro? En primera instancia, se sostiene que la defensa del patrón de cambio oro es motivada por la influencia e insistencia del presidente de la misión de expertos financieros. Pero hay otros posibles argumentos: a) la vigencia del patrón cambio oro en Estados Unidos de América; b) los fundamentos del propio sistema monetario, y $c$ ) la inflación, la pérdida del poder adquisitivo de los salarios, y el mal manejo de la moneda nacional en manos de la banca privada durante la vigencia de la ley de moratoria (o de inconvertibilidad) del 30 de agosto de 1914 .

La importancia del problema de esta investigación se debe a dos razones: primero, en la historia ecuatoriana, donde se describen los acontecimientos que originaron y que siguieron posteriormente a la revolución juliana, no se debaten las razones del porqué Ecuador se mantuvo en el patrón de cambio oro hasta febrero de 1932. Es más, cuando Isidro Ayora -presidente constitucional- renunció a su cargo en agosto de 1931 por la profunda crisis, transcurrieron más de cinco meses para que se decidiera por decreto de emergencia la salida del patrón oro. ¿ Por qué este régimen monetario duró más de cinco meses, si la salida del presidente constitucional se originaba por la insistencia en el patrón de cambio oro y la profundidad de la crisis que ocasionaba? Esto es algo que los diferentes historiadores monetarios no resuelven, y este estudio lo abordará, lo que muestra su originalidad. Además, se asume que después de la renuncia de Ayora se 
abandona el patrón de cambio oro o, en su caso, se expresa que el presidente encargado y su ministro de Hacienda acordaron en un principio y después ya no. Segundo, el estudio del patrón de cambio oro, la vigencia y sus efectos en la economía ecuatoriana, revelan que es una experiencia válida para un Ecuador en dolarización por ser regímenes monetarios casi idénticos en sus mecanismos de funcionamiento.

La estructura de este trabajo se conforma de siete partes, que respetan en lo posible el orden cronológico de los hechos. En la primera parte se especifica cuál es el problema de investigación, así como su importancia. En la segunda, se realiza un estudio de la economía política del patrón de cambio oro en Ecuador. En la tercera, se describen las bases técnicas del régimen monetario en estudio. En la cuarta, se detallan la influencia de Edwin Kemmerer y su misión de expertos en la persistencia de las autoridades económicas de no abandonar el patrón de cambio oro. En la quinta, se lleva a cabo un análisis macroeconómico -con la estadística disponiblesobre las causas de la resistencia de la economía ecuatoriana y del propio régimen monetario a la crisis económica, financiera y social. En la sexta, se explican los últimos días del patrón cambio oro y se resalta la defensa doctrinaria del presidente del Banco Central del Ecuador de la época, Enrique Cueva. Al final se presentan las conclusiones.

\section{EL PROBLEMA DE INVESTIGACIÓN Y SU IMPORTANCIA}

La economía ecuatoriana durante el siglo $\mathrm{xx}$, y en especial las primeras décadas, es una de las más atrasadas del continente. La dirigencia política del Ecuador aceptó importar instituciones con el objetivo de conseguir financiamiento para expandir el gasto público, satisfacer las necesidades de desarrollo e impulsar la modernización del Estado. Entre esas instituciones importadas estaba el patrón de cambio oro. La crisis de 1929 empujó a los países del mundo en desarrollo a ser los primeros en abandonar el patrón de cambio oro. En Sudamérica, de una manera u otra, los países fueron abandonándolo en su forma más ortodoxa; los casos más relevantes fueron Argentina y Paraguay.

Sin embargo, según Miño (2008), Ecuador fue el último de los países en hacerlo: "para enero de 1932, el Ecuador se había convertido en el único país sudamericano que mantenía el funcionamiento del patrón oro de la forma más ortodoxa". La obstinación por parte de la dirigencia política y de los responsables de la política económica por sostenerlo, esperando que "lo peor de la crisis pasará", llevó al país a una espiral deflacionaria donde se perdió gran cantidad de reservas de oro, y donde los costos sociales fueron altos. Otros países, como Argentina, lo abandonaron inme- 
diatamente (16 de diciembre de 1929), ya que, como menciona Rapoport (2008, p. 146), "El régimen de conversión sólo funcionaba en periodos de bonanzas". El problema de esta investigación radica en buscar las causas de que Ecuador haya abandonado tardíamente el patrón de cambio oro respecto a otros países de Sudamérica que lo abandonaron de forma casi inmediata, como en el caso de Argentina, después del derrumbe de la Bolsa de Valores de Nueva York en octubre de 1929.

Ecuador, en su historia económica, ha impuesto en múltiples ocasiones regímenes cambiarios rígidos, entre los que se encuentran: el clásico patrón oro de 1897, el patrón de cambio oro de 1927, el tipo de cambio fijo de los años setenta, y el actual régimen de la dolarización. Analizar las razones del prolongado tiempo en que perduró el patrón de cambio oro en un contexto de crisis persistente con shocks cada vez más repetitivos, en comparación con otros países de Sudamérica, es un importante caso de estudio para un Ecuador con dolarización, puesto que son regímenes monetarios que son prácticamente idénticos en su mecanismo de funcionamiento, en los objetivos por alcanzar, y en las restricciones a las que se subordina la economía. La importación de instituciones como política guarda debilidades, ya que muchas veces no se ajustan a las necesidades de desarrollo del país que adopta esas instituciones foráneas; y, por lo tanto, la política económica se encuentra cercenada para afrontar las presiones sociales. Así, el análisis de la obstinación por mantener el patrón de cambio oro es una experiencia válida para un Ecuador en dolarización, puesto que persistir en regímenes monetarios en extremo rígidos pone en riesgo el tejido social, económico y productivo de un país.

Por otro lado, esta investigación se justifica, ya que al comprobarse la hipótesis de que el abandono tardío se debe a la razón mencionada en la introducción, otros países que estuvieron bajo la influencia de Estados Unidos y de Kemmerer pueden someter a comprobación la misma hipótesis, poniendo énfasis en que hubo países como Argentina y Paraguay que lo abandonaron semanas después del desplome de 1929.

No obstante, antes de empezar a probar empíricamente que la hipótesis es verdadera, hay que aclarar si Ecuador en verdad fue el último en abandonar el patrón de cambio oro en Sudamérica. En el curso de esta investigación se encontró que Kemmerer (Arribaron a New York de regreso de Lima los delegados a la Conferencia Bancaria, y Kemmerer hizo varias declaraciones, 29 de diciembre de 1931, El Telégrafo) declaró a su llegada a Nueva York de la Conferencia de Bancos Centrales celebrada en Lima que "Las Repúblicas del Perú y el Ecuador están en pleno goce del régimen del Talón de oro; y los tres restantes países, Chile, Bolivia y Colombia tienen el régimen del oro, con restricciones en el cambio", y que Drake (1995, p. 
377) afirmó que el decreto oficial peruano de la inconvertibilidad fue en mayo de 1932 (véase cuadro 1).

Miño (2008) también afirma que Chile, Colombia y Perú mantienen a la par la cotización oficial para sus divisas, si bien no se permite el libre cambio con el extranjero. Esto último significaba el fin para el entramado del patrón oro, tal como lo señalan su funcionamiento y sus características de la forma más ortodoxa. Miño (2008) realiza esta afirmación con base en un editorial de Frank Fetter publicado en El Comercio del 30 de enero de 1932, y no la elabora a partir de documentos que muestren la salida de Perú del patrón de cambio oro antes de mayo de 1932 por restricciones a la salida de oro o cualquier otro mecanismo que viole su funcionamiento o característica.

¿Cuál puede ser la confusión? Eichengreen (2000) expresa que Brasil, Chile, Paraguay, Perú, Venezuela, Australia y Nueva Zelanda recortaron su patrón oro, lo que dificultó la obtención de oro, en un análisis posterior a octubre de 1929. Sin embargo, el patrón de cambio oro en Perú no se instauró hasta abril de 1931; Drake (1995, p. 361) señala que "durante el año de vigencia el oro y el capital fluyó al exterior".

Los autores antes mencionados están malinterpretando las acciones de la banca central peruana, cuando decidió retener en Lima la mayor parte de sus reservas en oro el 13 de enero de 1932, como medida precautelar de proteger sus reservas de los centros financieros de Londres y Nueva York, donde se especulaba con la salida de Estados Unidos del patrón oro y el posible embargo: "La parte más apreciable de las reservas de oro del Perú está actualmente en Lima" (El Perú retiene en Lima la mayor parte de sus reservas oro, 14 de enero de 1932, El Telégrafo). De esta manera, Ecuador fue el penúltimo en abandonarlo, si se realiza el análisis en su forma más ortodoxa.

\section{ECONOMÍA POLÍTICA DEL PATRÓN CAMBIO ORO}

Desde mediados del siglo XIX Ecuador se vinculó a la economía mundial mediante la división internacional del trabajo, y adoptó, al igual que el resto de los países de América Latina, el modelo agroexportador de crecimiento hacia afuera, tal como señalan Rapoport (2008) y Mörner (1989). El consumo de cacao se masificó en Europa y en Estados Unidos al finalizar el siglo XIX, lo que incrementó considerablemente la demanda de este producto primario. Así, los patrones de especialización de las exportaciones, y de la dependencia en África, Asia y América Latina se reforzaron. Este tipo de vínculo situó a Ecuador en una posición endeble, sujeto a las oscilaciones de los ciclos de auge y depresión del capitalismo mundial. 


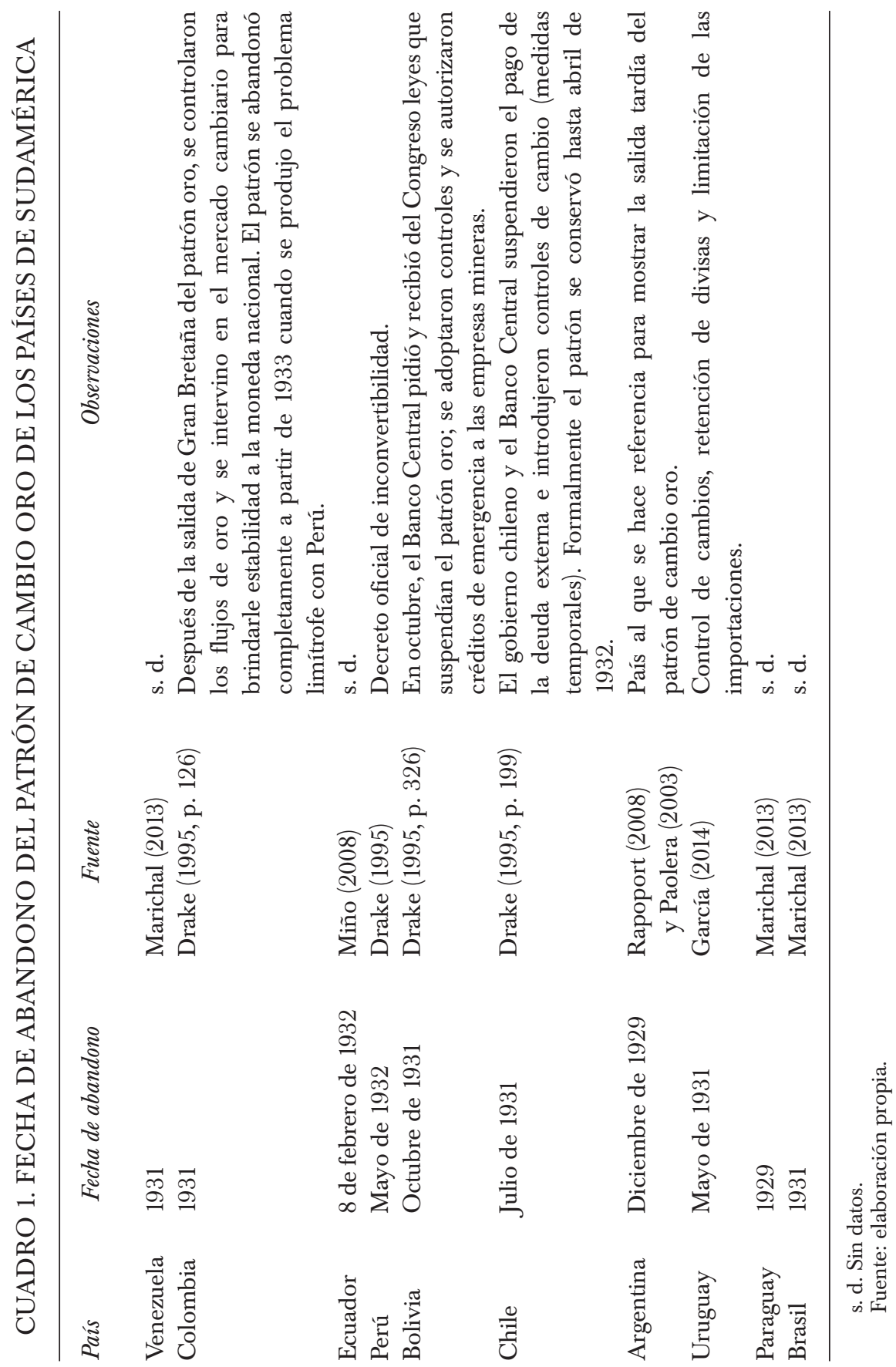


Del modelo agroexportador surgen dos instituciones claramente definidas: la moneda (el sucre) y un sistema bancario que actuaba como árbitro de la economía, puesto que impulsaba el negocio de la exportación y de la importación, y como prestamista del Estado. La revolución liberal y la lucha de su mayor exponente, Eloy Alfaro, por la modernización del Estado, desde 1895, aseguraron el control del Estado por parte de los exportadores cacaoteros y de los banqueros, lo que permitió establecer, tal como señala Acosta (2006, p. 61), "condiciones favorables para una articulación más estrecha de los mercados regionales y de la economía nacional en su conjunto con la economía mundial".

La dimensión del ciclo productivo del cacao -los árboles están maduros para su primera cosecha luego de cinco a siete años- causó que la adaptación a los ciclos económicos mundiales no fuera fácil. No obstante, según Mörner (1989), los grandes productores tenían un sistema financiero bien desarrollado, en el cual respaldaban sus actividades agrícolas de exportación. Con esa característica, los bancos de Guayaquil ganaron una creciente importancia (véase cuadro 2).

Chiriboga (2013) explica cabalmente la participación -protagonismode la banca privada en el engranaje del modelo agroexportador, basado en el cacao:

Los plantadores reciben de los bancos adelantos por sus entregas de cacao en consignación; los exportadores reciben sus giros del exterior a tantos meses plazo; los importadores envían sus giros a través de los bancos locales hacia la banca internacional, las rentas fiscales circulan a través de ellos, el gobierno recibe cuantiosos préstamos para llenar sus déficits fiscales; los terratenientes serranos monetarizan su renta en las sucursales bancarias; en fin, todo el funcionamiento de la acumulación agroexportadora parecería converger hacia el sistema bancario (p. 325).

Asimismo, el modelo agroexportador estaba influido por los lazos comerciales que la división internacional del trabajo imponía. Mörner (1989) afirma que la característica común en América Latina fue la creciente influencia de Estados Unidos, tanto en el comercio como en las inversiones, a costa, básicamente, de los ingleses. Entre la víspera de la primera guerra mundial y su finalización, Estados Unidos absorbió más de las tres cuartas partes de las exportaciones ecuatorianas. Según las cifras de Drake (1995, p. 208), entre 1913 y 1920, las exportaciones ecuatorianas a Estados Unidos pasaron de 24 a $56 \%$ del total, mientras que las exportaciones a Gran Bretaña tuvieron una rotunda caída para 1920. No existía sólo especialización en el tipo de producto de exportación, sino también concentración en los mercados de exportación. 


\section{CUADRO 2. BANCO COMERCIAL Y AGRÍCOLA (1902) Y BANCO DEL ECUADOR (1920). PRINCIPALES ACCIONISTAS (PORCENTAJES)}

\begin{tabular}{lcc}
\hline & \multicolumn{2}{c}{ Principales accionistas } \\
& $\begin{array}{c}\text { Banco Comercial } \\
\text { y Agrícola (1902) }\end{array}$ & $\begin{array}{c}\text { Banco del } \\
\text { Ecuador (1920) }\end{array}$ \\
& 52.2 & 13.45 \\
Hacendados exportadores & 3.5 & 11.7 \\
Importadores hacendados & 6 & 3.51 \\
Exportadores & 20.9 & 29.82 \\
Importadores & 0 & 26.32 \\
Importadores industriales & 2 & 15.2 \\
Propietarios cacaoteros & 15.4 & 0 \\
Accionistas principales no identificados & 100 & 100 \\
Total & & \\
\hline
\end{tabular}

Fuente: elaboración propia con base en Chiriboga (2013, pp. 330 y 336).

Para 1926, el comercio exterior ecuatoriano refleja un mayor peso con Estados Unidos de América, tanto de las exportaciones como de las importaciones, respecto al Reino Unido: 43 y 39\% de las importaciones y exportaciones ecuatorianas proceden y van a Estados Unidos, respectivamente, mientras que 21 y $5 \%$ de las importaciones y exportaciones se establecen con el Reino Unido, respectivamente (véase gráfica 1). A pesar de esta diferencia ventajosa para Estados Unidos respecto al Reino Unido en el comercio exterior ecuatoriano, aquel perdió terreno desde 1920, lo que impulsó a crear nuevos mecanismos institucionales para reforzar los lazos comerciales como se vislumbrará más adelante.

Los grandes ingresos generados por la fácil expansión de la economía de exportación durante las dos primeras décadas del siglo Xx forzaron a los regímenes modernizantes a optar por una pacífica convivencia con el anticuado orden social tradicional, todavía prevaleciente. ${ }^{1}$ Muy aparte del gobierno y su tendencia ideológica, poderosos terratenientes conservaron el control de facto de la población rural. El sistema no permitiría nin-

${ }^{1}$ En Ecuador, el problema Iglesia-Estado, a causa de la extrema posición que el líder conservador Gabriel García Moreno había asumido, en términos ideológicos se mantenía mucho más difícil que en los otros dos países. Después de la victoria militar de Eloy Alfaro en 1895, este político liberal lideró la elaboración de la Constitución de 1906, donde se consagró la separación de la Iglesia y el Estado. Los bienes rurales de la Iglesia fueron nacionalizados para fundar hospitales públicos. 


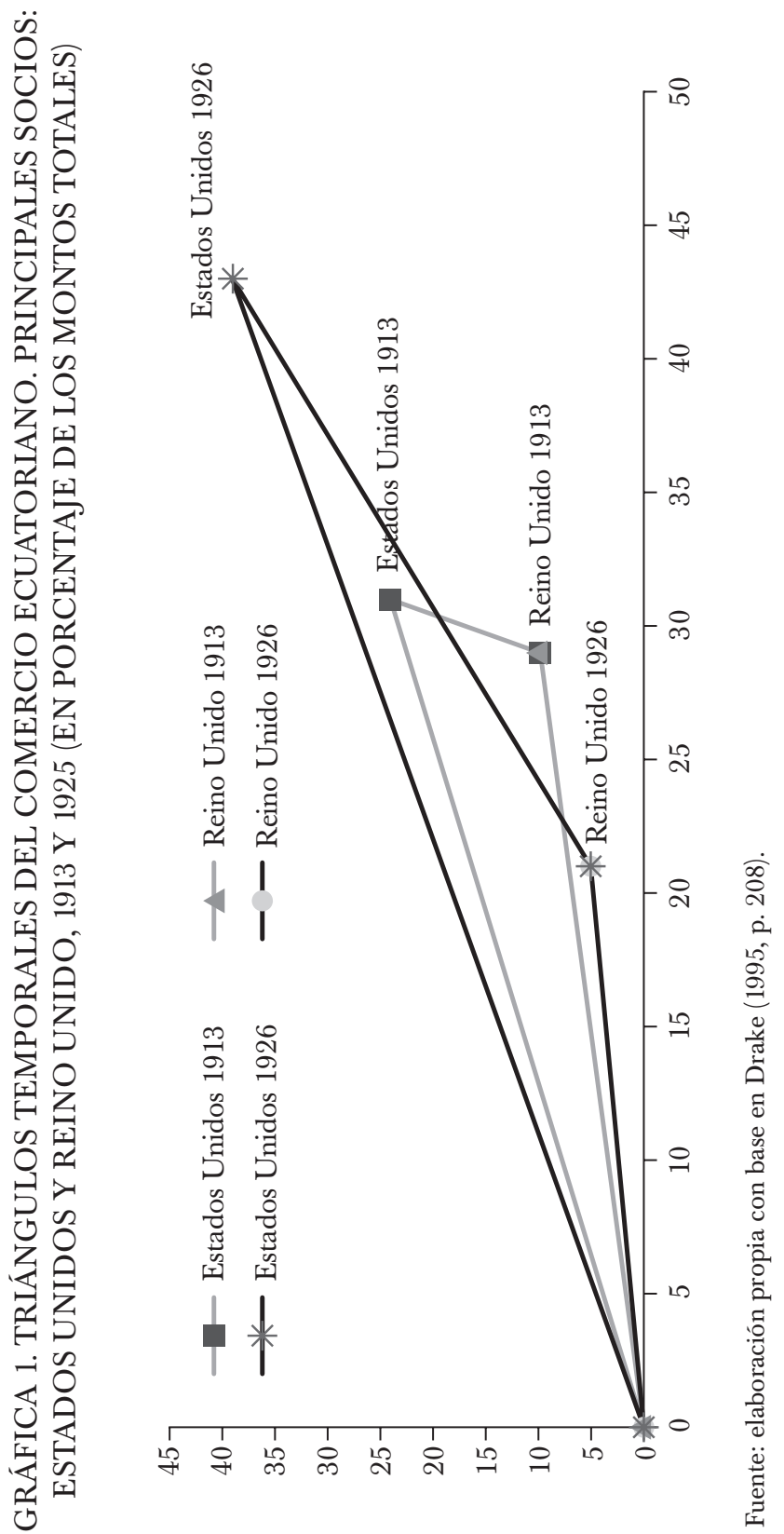


gún cambio radical. ${ }^{2}$ Sin embargo, impactos externos de gran relevancia, como la primera guerra mundial, hicieron difícil la estabilidad del sistema político instaurado en los años previos con base en la unión de los terratenientes costeños, la banca guayaquileña y la sumisión de una amplia capa de la población que se encontraba empobrecida.

A comienzos del siglo XX sólo existían bancos privados, cuatro eran de emisión: Banco Comercial y Agrícola (1894) y Banco del Ecuador (1868) en Guayaquil, Banco del Pichincha (1906) en Quito y del Azuay (1913). Estos bancos se regían por la ley de bancos de 1898, que instauró el patrón oro (1900-1914). El Banco Comercial y Agrícola con Francisco Urbina Jado y el Banco del Ecuador con Eduardo M. Arosemena -como gerentes- tuvieron visiones y acciones contrapuestas respecto al orden monetario, financiero y bancario que debería imperar. ${ }^{3}$

Estas discrepancias se agudizaron cuando el presidente Leónidas Plaza (septiembre de 1912-agosto de 1916), gobierno postalfarista, expidió ilegalmente la ley de inconvertibilidad, que puso fin al patrón oro el 6 de agosto de 1914. La ilegalidad cometida fue propiciada por la situación caótica del Banco Comercial y Agrícola. Fue un escenario muy distinto al del Banco del Ecuador hasta la muerte de su gerente, en 1917 (Miño, 2008, p. 37). Aunque el banquero Víctor Emilio Estrada era defensor de la ley por encontrarla necesaria ante la situación económica del país, el fin era favorecer al Banco Comercial y Agrícola y financiar al Estado, como ya era la política de los bancos, a pesar de la vigencia del patrón oro ( $\mathrm{Paz}$ y Miño, 1997, p. 55).

A lo largo de la primera guerra mundial los presidentes aumentaban paulatinamente su dependencia de los préstamos otorgados al Estado por el Banco Comercial y Agrícola de Guayaquil a medida que la inflación aumentaba considerablemente las tensiones sociales. Según sostiene Mörner (1989), “en Guayaquil, los salarios nominales permanecieron prácticamente invariables, entre 1914 y 1920, mientras que los precios de los principales alimentos subieron un 73\%” (p. 29) (véase gráfica 2).

A medida que los términos de intercambio eran desventajosos para Ecuador, por la caída del precio del cacao, el Banco Comercial y Agrícola reforzaba la política de emisión monetaria para combatir la adversa tendencia del comercio mundial permitiendo la subida de los precios internos

${ }^{2}$ Ayala (1988, p. 138) al identificar esta etapa la califica como "el triunfo político de la burguesía". Este autor señala que la revolución liberal fue "el vehículo y la expresión política de la burguesía ecuatoriana. Y el 'Estado laico' instaurado con la revolución fue el producto de transformaciones y reformas impulsadas por la burguesía que, en conjunto, representan un momento crucial en la constitución del Estado nacional en el Ecuador".

${ }^{3}$ En primera instancia, en esto se fundamentaban las guerras bancarias en el corazón del modelo agroexportador. 


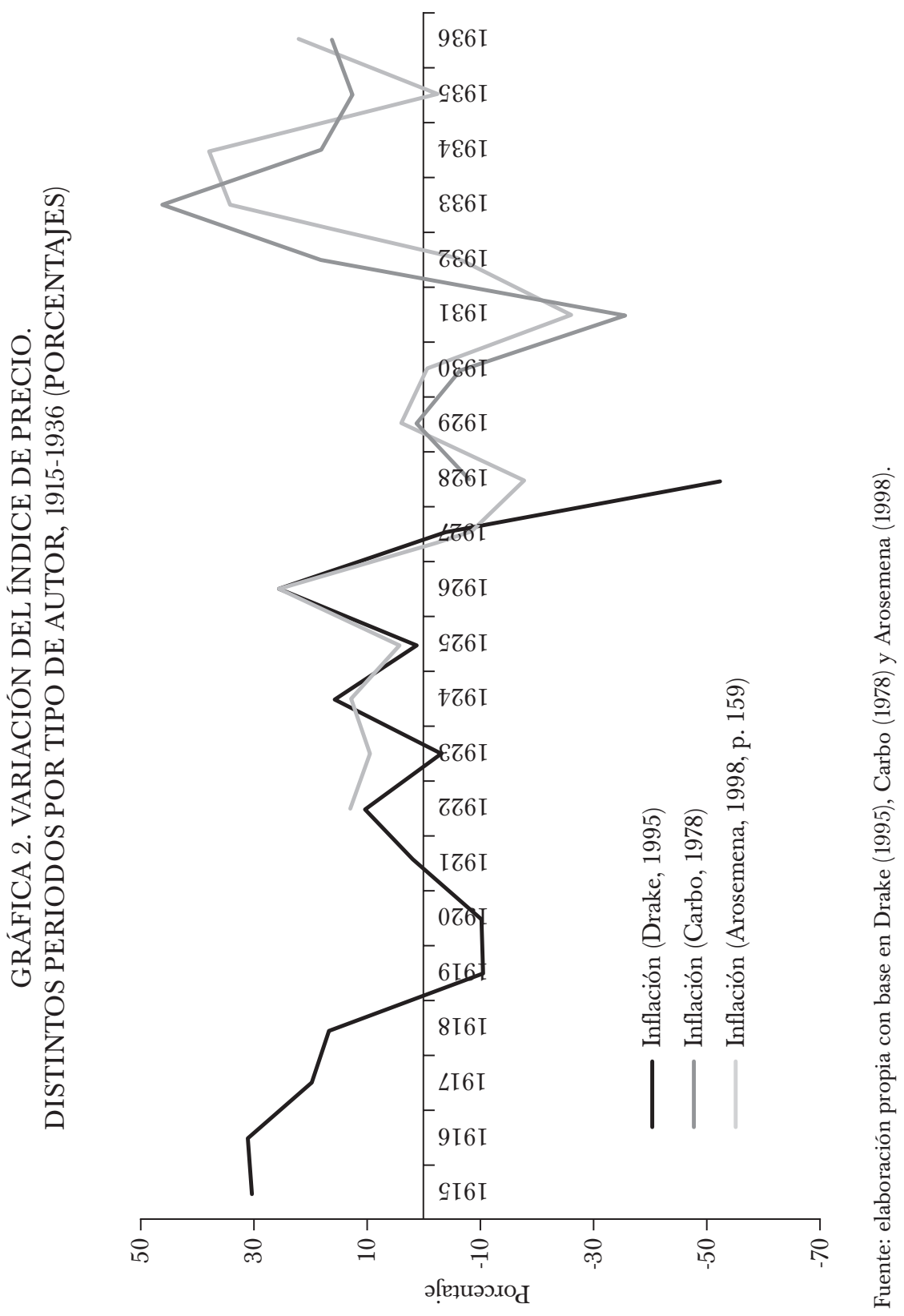


con desastrosas consecuencias sociales que llevaron a la huelga general de desempleados, reprimida con una masacre el 15 de noviembre de 1922.

Desde 1920, el precio del cacao experimentó la disminución más fuerte de todo el auge: según Chiriboga (2013, p. 258) en 1921 y 1922 se ubicó en 12.6, y en 16.3 sucres por quintal, respectivamente. En 1922, el precio del cacao era menos de la mitad de tres años atrás. Esta caída del precio del cacao, como expresión de la deflación mundial, se sumó a la caída de la producción por efecto de las plagas: la producción de cacao disminuyó en 214425 quintales entre 1924-1922, y en 1926 representaba un poco más de la mitad de lo alcanzado en 1921. Acosta (2006, p. 82) afirma "cuando a partir de 1924 se produjo la recuperación de los precios, el Ecuador, por efecto de las plagas mencionadas, ya no estuvo en capacidad de recuperar el terreno perdido" (véase gráfica 3).

Al verse librada de las restricciones que le imponía el patrón oro, la banca dominó por completo la economía nacional desde Guayaquil. No obstante, la puesta en evidencia de las debilidades siempre omnipresentes en el modelo agroexportador provocó que se desarrollara un fenómeno social que imperiosamente desembocó en un proceso político para instaurar un cambio económico caracterizado por la modernización del Estado.

Sin embargo, este proceso social se profundizó al punto de involucrarse en los acontecimientos sangrientos de noviembre de 1922, por la extrema desigualdad de la riqueza y del ingreso apuntalado por el atrasado desarrollo económico. A pesar de la ausencia de estadísticas oficiales (y rigurosamente tratadas) que denoten dicho atraso, se pueden extraer varias características de aquella época con base en ciertos recursos bibliográficos: las exportaciones per cápita de Ecuador durante el periodo 1925-1929 eran las más bajas de todos los países de América Latina. Según cifras de Bértola y Ocampo (2010, p. 98), el coeficiente de Chile, el país con las exportaciones per cápita más altas del continente, era 8.2 veces más alto que Ecuador. Aunque el desarrollo demográfico ecuatoriano fue más dinámico, Mörner (1989, p. 50) señala que las tasas anuales de crecimiento poblacional de los países andinos estuvieron por debajo de los otros países de América Latina. En 1913 y 1930, existían 0.35 y 0.59 km de vías férreas, respectivamente, por cada 1000 habitantes en Ecuador, lo que era superado por países como Bolivia y Panamá. Argentina, en 1930, tenía 3.29 km por cada 1000 habitantes, y en 1927, algo más de 13\% del presupuesto del gobierno se destinaba al gasto en obra pública.

Los regímenes postalfaristas tuvieron su ocaso cuando se volvió a imponer el tradicional mecanismo de fraude que permitió que ganara la candidatura a la presidencia de Gonzalo S. Córdova, cuyo gobierno duró 


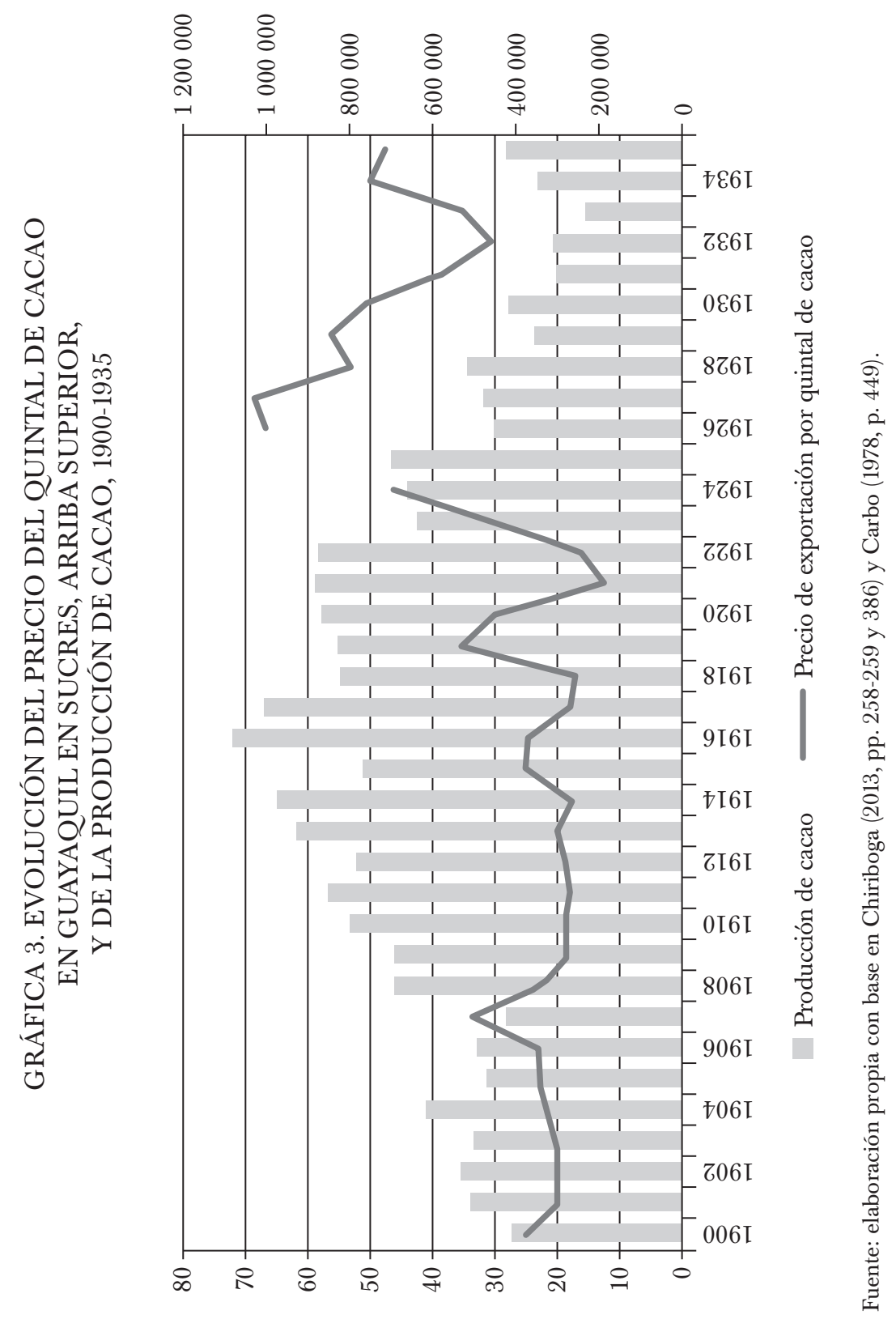


hasta que surgió la revolución juliana (1 de septiembre de 1924-9 de julio de 1925). ${ }^{4}$ Mörner (1989, p. 62) describe esta situación:

Lo que diferencia al Ecuador de los otros países andinos (Perú y Bolivia) es el relativo equilibrio regional entre los segmentos de las clases altas radicadas en Quito y Guayaquil. En efecto, este equilibrio había sido alterado durante el ascenso liberal durante el auge del cacao de 1895 a 1925 pero, con la revolución de 1925, fue restituido. Como resultado, la clase alta se encontró más dividida que nunca entre divergentes lazos e intereses económicos, lo que la forzó a permitir una mayor participación política de otros grupos, las clases medias, y los militares, especialmente.

La revolución juliana fue la expresión de un proceso social convertido en político, agudizado por las paupérrimas condiciones sociales de gran parte de la población. Así, el sistema político de exclusión extrema tiene como motor el modelo agroexportador y el desequilibrio regional era su mayor manifestación, pero a la vez su "espada de Damocles". El mencionado desequilibrio impulsó las constantes conspiraciones hasta que el descontento social fue canalizado por el ejército, una oficialidad joven, que con la actuación de varios industriales y políticos de la sierra derrocaron a Gonzalo S. Córdova. ${ }^{5}$ De acuerdo con Paz y Miño (2013), lo primero por destacar de esta revolución fue la oficialidad joven que estaba inspirada en ideales patrióticos, nacionalistas, y socialreformistas.

Una de las primeras medidas después del 9 de julio de 1925 fue el apresamiento de Francisco Urbina Jado, gerente del Banco Comercial y Agrícola, y la regulación y control del sistema bancario. En enero de 1926 se nombró una nueva junta provisional, la segunda, y con ello, la toma de posesión de Isidro Ayora Cueva, como presidente provisional de la república, lojano de nacimiento y alcalde de Quito en 1925. Posteriormente, Isidro Ayora fue presidente constitucional interino en octubre de 1928 y presidente constitucional de la república de abril de 1929 hasta el 24 de agosto de 1931. Por último, la revolución juliana expresó el tránsito del liberalismo hacia el socialismo. Por eso favoreció la constitución del Partido Socialista Ecuatoriano, el 28 de marzo de 1926. Luis Napoleón Dillon, industrial y comerciante quiteño, e integrante y ministro de Hacienda de la primera junta provisional, fue socialista.

\footnotetext{
${ }^{4}$ Según Ayala (1988, p. 165), en condiciones no fraudulentas quien hubiera ganado la elección habría sido el coronel Juan Manuel Lasso "hombre de gran popularidad".

${ }^{5}$ La primera junta de gobierno provisional, según Paz y Miño (2013, p. 28), se integró con cuatro vocales por la sierra y tres de la costa.
} 
Hay que resaltar que la revolución juliana, y sus formas de gobierno hasta agosto de 1931, condenaron la llamada plutocracia y el desorden monetario causado por esta. Se evidencia que esta condena tenía como objetivo la reestructuración del poder que emergía de los banqueros, pero sin pensarlo; con la instauración del segundo patrón oro, se llevó al sistema bancario a una peligrosa autodepuración. Nuevos actores surgieron de este proceso económico. ${ }^{6}$

Samaniego (1988, p. 100), al interpretar la situación económica de los años veinte, expresa que "la verdad de las cosas era que no se trataba de una crisis monetaria, sino de una crisis causada por la deficiente estructura productiva". ${ }^{7}$ La crisis reveló el profundo desequilibrio regional: con la producción cacaotera, y su exportación, se formó y consolidó el sistema bancario donde el crédito tenía principal destino a Guayaquil, se crearon diferencias salariales (la costa frente a la sierra), se impulsó el comercio importador, y se agudizó la desigualdad del ingreso y de la riqueza. ${ }^{8}$

Se puede decir que la costa representaba la transformación de las relaciones sociales de producción precapitalista a capitalista, mientras que la sierra mantenía una economía de subsistencia, esencialmente agrícola, con una producción artesanal rudimentaria. Cueva (2007, p. 107), al comparar la economía chilena frente a la ecuatoriana, en un ejercicio metodológico y teórico, se refiere a esta última como la "feudalidad empedernida del altiplano". ${ }^{9}$ En este escenario se inició el proyecto de modernización de la revolución juliana.

\section{BASES TÉCNICAS DEL PATRÓN DE CAMBIO ORO}

En el primer lustro de los años veinte la inconvertibilidad de las monedas (y la continua depreciación) ocasionó que la inflación aumentara por la

\footnotetext{
${ }^{6}$ En una investigación inédita, Naranjo (2017) sostiene que "El movimiento Juliano empezó entonces a ser secuestrado por distintos grupos de presión. El proyecto inicial de fundación del Banco Central comenzó a sufrir tropiezos y sólo se aceptaba su viabilidad si recibía el aval de los Estados Unidos." Además, con base en las actas del Directorio del Banco Central del Ecuador de mayo y junio de 1927, afirma que quien ejercía la presidencia del fundado Banco Central, Neptalí Bonifaz, "generó el primer salvataje bancario que recuerde el país." El banco privado que se salvó fue el Banco Pichincha.

${ }^{7}$ Más adelante se analizará con detenimiento esta aseveración.

${ }^{8}$ Mörner (1989) señala que el sistema político provocó la profunda división de la sociedad: una clase que se encontraba en el bienestar, el lujo, y la sofisticación obsesivamente parisina (muy minoritaria), frente a otra que se hundió en la extrema miseria humana. El sistema político fue el resultado de un sistema de estrecha especialización exportadora para el mercado mundial.

${ }^{9}$ Aunque la frontera agrícola se había extendido desde mediados del siglo XIX, en cifras de Arosemena (1990), para 1920, 94\% de las exportaciones pertenecían a la costa; mientras que 6\%, a la sierra. Esta situación cambió muy levemente desde 1900.
} 
excesiva expansión de circulante, lo que desestabilizó la producción. Por lo tanto, como afirma Marchán (1989), la superación de los problemas económicos de la posguerra debía comenzar por el retorno a un régimen internacional de patrón oro.

Las características eran que los gobiernos determinan el precio del oro en sus respectivas monedas, definido como valor prioritario. Las autoridades monetarias adquieren el compromiso de garantizar la convertibilidad de las monedas nacionales en oro; y los gobiernos se ajustan a la regla de ligar la creación de dinero a sus posesiones de oro.

Como resume Marchán (1989), "bajo el régimen del talón oro la masa monetaria no es una variable autónoma o dependiente de la voluntad de las instituciones rectoras de la política monetaria, sino que su comportamiento responde a la existencia de oro" (p. 111).

Así, la depreciación y la inflación del primer lustro de los años veinte incentivaron la reinstauración del patrón oro. No obstante, el problema principal para ese objetivo eran las escasas existencias mundiales de oro. Durante la primera guerra mundial las monedas de oro casi habían desaparecido de la circulación. La escasa reserva de oro entró en contradicción frente a una economía mundial que distaba mucho de su tamaño a la de los años de 1870, situación análoga para casi todos los países. Por lo tanto, como señala Eichengreen (2000), "para estirar aún más las reservas de oro existentes (y contar así los niveles tradicionales de respaldo de una oferta monetaria mayor), era extender la práctica que se seguía antes de la guerra y que consistía en complementar el oro con divisas, es decir, en transformar el patrón oro en un patrón de cambio-oro" (p. 87).

Siguiendo a Eichengreen (2000), las razones sobre la concentración de reservas oro en los bancos centrales y de complementarlo con divisas se debían al temor de una escasez mundial de oro.

No obstante, una vez "solucionado" el problema de la escasez, el problema del patrón cambio oro se convirtió en un asunto interno de los países. Las naciones que lo adoptaban aceptaban sacrificar la estabilidad de precios interna con tal de mantener una paridad fija de su tipo de cambio. Hollihan (1989) señala que

Nadie cuestiona que la deflación (caída continua en los precios) tuvo algo que ver o fue causada, en alguna proporción, por la contracción en el medio circulante. Nadie cuestiona, tampoco, que parte de la deflación interna producida en el país pudo ser causada, no por un efecto monetario directo al contraerse el medio circulante; sino también por un efecto directo al reducirse los precios en el extranjero (p. 21). 
En este sentido, comprometerse con un sistema monetario como el patrón oro significaba relegar la política comercial y fiscal a un segundo plano para sostener el sistema monetario. Eichengreen (2000) plantea que "debemos preguntarnos si cabe esperar que los gobiernos del siglo XIX comprendieran que el patrón oro favorecía la deflación. Es razonable esperar que comprendieran la naturaleza del problema, pero no su magnitud" (p. 27). ${ }^{10}$

El funcionamiento del patrón oro en la década de los años veinte había actuado en contra de la estabilidad de precios a escala mundial, cuando el argumento clave de su restauración había sido precisamente mantener tal estabilidad. Esta promesa incumplida provenía de la ausencia de un proceso de convergencia (distintas paridades adoptadas por los países, la magnitud de la deflación previa a la adopción del patrón de cambio oro, la distinta posición de los países en la cantidad de reservas de oro y la renuncia de aquellos países que concentraba gran cantidad de reservas para prestarlas a los países con déficit).

Prebisch (1995) expresó que existe estabilidad monetaria cuando el oro ingresa y egresa del Banco Central (y del país). Sin embargo, esto tiene un costo: inestabilidad en las actividades económicas. Al expandirse y contraerse la economía nacional de acuerdo con los vaivenes de la estabilidad monetaria exterior existe gran desperdicio de energía y recursos de la sociedad. Prebisch (1995) afirma: "Si la depresión es intensa y prolongada y se expande fuertemente el crédito para combatirla, llegará un momento en que tendrá que abandonarse el patrón oro por haber llegado esas reservas a peligrosos extremos” (p. 116). En esa línea, Marchán (1989) afirma que:

las autoridades monetarias sólo pueden emitir dinero comprando oro al público, es decir, únicamente si aumentan (disminuyen) la reserva en oro puede incrementarse (reducirse) la oferta monetaria. El crecimiento o recorte de la cantidad de circulante opera automáticamente en función del porcentaje de cobertura del oro, que puede ser del ciento por ciento o, como en Ecuador, del 50 por ciento; la cobertura no es otra cosa que el respaldo en oro de la emisión monetaria (p. 111).

En Ecuador, la nueva ley de monedas, expedida el 19 de marzo de 1927 y con registro oficial 289, instauró el segundo patrón oro y dispuso que la paridad del sucre frente al dólar tuviera una relación de cinco a

\footnotetext{
${ }^{10}$ Hay que recordar que el contexto social, laboral y político de la instauración del patrón oro en el siglo XIX dista mucho de los años veinte del siglo XX.
} 
uno. ${ }^{11}$ El circulante disminuyó, no obstante, de 58573781 a 50758253 sucres entre 1927 y 1928; esto se debió en gran parte a la ardua tarea del instituto emisor para retirar de la circulación los billetes viejos de los bancos emisores e imponer legalmente las especies monetarias únicas del Banco Central.

La nueva ley asignó al sucre un contenido de oro fino de 0.300933 gramos, equivalente a $20 \%$ del contenido de un dólar de Estados Unidos, de donde nace la equivalencia de cinco sucres por cada dólar estadunidense. ${ }^{12}$ En la exposición de motivos de la ley de monedas, la misión de consejeros financieros sostiene (Misión de expertos financieros. Exposición de Motivos de la Ley de Monedas, Quito, Ecuador, 19 de marzo de 1927 en Paz y Miño, 2013, p. 150):

La Misión no vacila en declarar que cualquiera tentativa de volver a la paridad antigua de 2.0547 sucres por dólar sería excesivamente desacertada. La posibilidad de restaurar la antigua paridad del sucre es, en verdad, muy dudosa; pero aun si fuera posible llevar a efecto tal empresa, mediante un programa de deflación, el proceso de revalorización sería extremadamente doloroso, se extendería en un periodo considerable de años y causaría muchos sufrimientos y grandes perturbaciones en la vida económica del país.

No obstante, cuando a Kemmerer le tocó asesorar a otros países como México en 1917, Turrent (2015) sostiene que, con base en una reflexión del consejero principal, el tipo de cambio de la moneda nacional, necesariamente súper fijo e inamovible por tratarse de un esquema de talón oro, debería ser el mismo que se había determinado en ocasión de la reforma monetaria de 1905. ¿Por qué el cambio de opinión? La respuesta se encuentra en la misma exposición de motivos de la ley de monedas de la misión de expertos, al contestar la pregunta (Misión de expertos financieros. Exposición de Motivos de la Ley de Monedas, Quito, Ecuador, 19 de marzo de 1927 en Paz y Miño, 2013, p. 164):

¿Qué contenido de oro debería adoptarse para la unidad monetaria del país? [...] Por razones de orgullo nacional y para el mantenimiento del crédito de un país, hay obvias ventajas en restablecer la antigua paridad legal de la moneda, como lo han hecho recientemente Dinamarca, Gran Bretaña y la Unión de Sud África.

${ }^{11}$ En 1898, el gobierno liberal de Eloy Alfaro, asesorado por el Banco del Ecuador, estableció el patrón oro (clásico), por vez primera en Ecuador con base en un "acuerdo de caballeros" entre banqueros, importadores y exportadores. De 1900 a 1913 el cambio se mantuvo estable, con ligeras variaciones que iban de 1.91 a 2.15 por dólar (Acosta, 2006; Miño, 2008).

${ }^{12}$ Según Oleas (1995), esto significó una devaluación de $41.1 \%$ y la total alineación de la economía ecuatoriana con la de Estados Unidos. 
Pero, cuando la depreciación de la moneda ha continuado por un largo periodo de tiempo, y cuando el valor oro ha caído muy abajo de la paridad, los males que acompañan a una deflación extensa y continuada por largo tiempo, que se impone como condición indispensable para restablecer la antigua paridad oro de la moneda, son mucho mayores que todas las ventajas que de este esfuerzo pueden derivarse (art. 1).

En los cálculos de Oleas (1995) la respuesta es:

Los científicos explicaron que esta cifra tenía dos ventajas: por un lado, evitaba un injusto beneficio para los acreedores externos; y, por otro, impedía que los exportadores percibieran menos sucres por sus exportaciones. [...] Este nivel cambiario, fijado rígidamente, constituía un claro beneficio al sector transable de la economía: exportadores que obtendrían de partida una ganancia adicional de 4 por ciento y deudores que verían reducirse en ese mismo 4 por ciento el valor real de sus obligaciones internacionales (p. 12). ${ }^{13}$

El cambio de opinión está cimentado en el debate sobre la paridad de la libra esterlina entre el economista J. M. Keynes y W. Churchill. Según Eichengreen (2000, p. 85) "es posible que Churchill temiera que la vuelta al oro a un tipo devaluado privara a la política económica de sus ventajas". La devaluación (o un tipo de cambio distinto al fijado antes de la guerra) sería sinónimo de falta de credibilidad. Por lo tanto, para que el compromiso de Gran Bretaña con el oro fuera creíble, había que restablecer la convertibilidad a la paridad existente antes de la guerra; si no, se entendería que las autoridades al redefinir la paridad una vez podían estar dispuestas a hacerlo de nuevo.

Según lo demuestra la exposición de motivos de la ley de monedas, para febrero de 1927 Kemmerer estaba seguro de las debilidades que tendría el patrón oro en Ecuador si se restablecía la paridad legal de la moneda antes del inicio de la primera guerra mundial, con base en la experiencia de Gran Bretaña, de las opiniones de Keynes, y de Francia en el acaparamiento de oro iniciado en 1925 (Misión de expertos financieros. Exposición de Motivos sobre la Ley Orgánica del Banco Central del Ecuador, Quito, Ecuador, 11 de febrero de 1927 en Paz y Miño, 2013). Turrent (2015) señala, para el caso de México, la situación del patrón con la paridad anterior a la primera guerra mundial. Para 1931, Kemmerer

${ }^{13}$ Según Oleas (1995), Kemmerer justificó su análisis en que la cantidad de dinero en la economía estaba acorde con el volumen de negocios en el país, a un valor oro de 20 centavos de dólar, más o menos, por sucre. 
había declarado que los indicadores del tipo de cambio estaban cercanos a la inflación (Miño, 2008, p. 85).

Sin embargo, para comprender la salida tardía de Ecuador del patrón oro es necesario establecer no sólo a qué paridad se fijó su instauración, sino también cómo se normó la independencia del Banco Central. El artículo 3 de la Ley Orgánica del Banco Central de Ecuador del 12 de marzo de 1927 estableció: "La duración del Banco será de cincuenta años, que empezarán a contarse desde la fecha de registro de la escritura social, y este término podrá prorrogarse por plazos determinados, a petición del Banco, por resolución del poder ejecutivo, previa autorización especial del Congreso."

En la exposición de motivos de la misión de expertos financieros se aconsejaba que el plazo para la concesión del banco fuese lo bastante amplio para mantenerlo apartado de la política y permitirle operar de una manera eficiente y permanente. Sin embargo, la base fundamental de la independencia, como se verá más adelante, fue el artículo 5, que expresa: "Declárase que el Banco Central es una institución de derecho privado, y, por consiguiente, que el Estado no asume responsabilidad pecuniaria alguna respecto del resultado de sus operaciones, excepto en lo especialmente estatuido en la presente ley."

Es una institución de derecho privado, porque los bancos comerciales y secciones comerciales de otros bancos que operaban en Ecuador contribuían al capital del Banco Central en una proporción equivalente a 15\% del respectivo capital pagado y fondos de reserva de cada banco.

\section{INFLUENCIA DE EDWIN WALTER KEMMERER}

Una de las motivaciones más importantes de la investigación de Drake (1995) era analizar las verdaderas intenciones económicas y políticas de las autoridades ecuatorianas con respecto al asesoramiento técnico extranjero, interrogándose cómo, por qué, y para quiénes fue exitoso. Esas verdaderas intenciones eran que los gobiernos andinos deseaban asesores extranjeros sobre todo para atraer inversionistas extranjeros, financiamiento, y para consolidar internamente la estabilidad política. ${ }^{14}$

Drake (1995) afirma que entre la primera y la segunda visita de Kemmerer en Colombia (1923-1930) la deuda externa pública se incrementó cerca de diez veces. Chile casi triplicó su endeudamiento externo después de la misión Kemmerer en 1925. El ministro de Finanzas de Bolivia en

\footnotetext{
${ }^{14}$ Sin embargo, Drake (1995, p. 25) se refiere a la comisión de expertos de forma más puntual como "mediadoras de transferencia de tecnología y estructuradoras de instituciones".
} 
forma explícita presionó al Congreso para aprobar la legislación de Kemmerer en 1927-1928, para que el gobierno, con un profundo déficit fiscal, pudiese obtener capital externo. El Congreso de Perú aprobó en un solo día la ley del Banco Central Kemmeriano en 1931, incluso sin leerla, en una carrera desesperada para que los banqueros estadunidenses salvaran al país de la depresión. Sin embargo, como el préstamo de emergencia no llegó, la mayor parte de los proyectos de ley de Kemmerer se archivaron.

Pero, más allá de las verdaderas intenciones de las elites ecuatorianas, otro punto que se debatió con fuerza fue la influencia de Estados Unidos en los países andinos a través de la comisión de expertos. La creciente integración de los países andinos con Estados Unidos, por medio de los canales comerciales y financieros, era algo inevitable después de la apertura del Canal de Panamá y de la destrucción de Europa durante la primera guerra mundial (véanse gráfica 1 y cuadro 3 ). ${ }^{15}$

El tema de discusión no era si Sudamérica debía profundizar su dependencia con el coloso del Norte, sino más bien cuánto más, y de qué manera lo tendría que hacer. Un convencido de los beneficios del laissez faire, Edwin W. Kemmerer, persuadió a los países asesorados de reducir los obstáculos al libre flujo de los bienes y del capital. Para ello se identificaron la "herencia institucional ibérica" y las monedas depreciadas como los mayores impedimentos a la expansión comercial de Estados Unidos en América Latina. ${ }^{16}$

E. W. Kemmerer fue el innovador en la aplicación de métodos estadísticos al estudio del dinero. Se apegó al debate sobre la teoría cuantitativa del dinero y afirmó que la inflación representaba un peligro mayor que la deflación.

${ }^{15}$ Gran Bretaña perdió su hegemonía en los Andes después de la primera guerra mundial: entre 1913 y 1929 la participación de Inglaterra en las importaciones mundiales bajó de 16 a 15\% y en las exportaciones mundiales, de 14 a 11\%. La participación británica en las exportaciones e importaciones de los países del Pacífico disminuyó en mayor proporción que el de todo su comercio alrededor del mundo. El ocaso de la economía británica y de su influencia en los países andinos se profundizó con la apertura del Canal de Panamá, lo que provocó que estos países multiplicaran sus intercambios con Estados Unidos hasta fines de la década de los veinte. Las inversiones estadunidenses en Sudamérica se multiplicaron por ocho, aproximadamente.

${ }^{16}$ Un debate acerca del pensamiento económico de Kemmerer es el tamaño del Estado. Drake (1995, p. 60) sostiene que Kemmerer "contribuyó a un notable crecimiento del Estado en los países andinos, a pesar de su adhesión al liberalismo". No obstante, si se entiende por laissez faire permitir que los individuos busquen sus propias actividades dentro de los límites de la ley, el orden y el respeto por los derechos de propiedad, entonces el libre flujo de bienes y de capital debería asentarse en un Estado organizado e institucionalizado. En Ecuador existía un Estado envuelto en una larga guerra bancaria cuya mayor expresión era la excesiva emisión monetaria. Por lo tanto, Ecuador, en medio de su profundo atraso económico e institucional, necesitaba de un Estado con mayor presencia en la economía, y aquello no representaba una contradicción en el pensamiento de Kemmerer, puesto que el Estado era una necesidad para establecer el laissez faire. 
CUADRO 3. INVERSIONES DE ESTADOS UNIDOS EN AMÉRICA LATINA, 1914-1930 (MILLONES DE DÓLARES ESTADUNIDENSES)

\begin{tabular}{|c|c|c|c|c|c|c|}
\hline & \multicolumn{2}{|c|}{ Inversiones directas } & \multicolumn{2}{|c|}{ Inversiones indirectas } & \multicolumn{2}{|c|}{ Inversiones totales } \\
\hline & 1914 & 1930 & 1914 & 1930 & 1914 & 1930 \\
\hline América Latina & 1281 & 3634 & 368 & 1610 & 1649 & 5244 \\
\hline Sudamérica & 323 & 1631 & 43 & 1411 & 366 & 3042 \\
\hline Colombia & & 130 & & 172 & 22 & 302 \\
\hline Ecuador & & 12 & & 0 & 9 & 12 \\
\hline Perú & & 125 & & 75 & 63 & 200 \\
\hline Bolivia & & 62 & & 54 & 11 & 116 \\
\hline Chile & & 441 & & 260 & 181 & 701 \\
\hline
\end{tabular}

Fuente: Drake (1995, p. 40).

Su relación con el gobierno estadunidense comenzó con el encargo de conducir a Filipinas hacia el patrón oro en 1903. El departamento de Estado lo recomendó como consejero de los gobiernos de Guatemala y Colombia en 1919 y 1923, respectivamente. En este último país obtuvo su primera misión completa. Drake $(1995$, p. 35) señala que, a juicio de Kemmerer, sus asesorías eran "una ilustración técnica que permitía crear instituciones eficientes, libres de la influencia corrupta de la política y del privilegio".

Entre los intereses de las autoridades y de una fracción de la elite ecuatoriana que se beneficiaban con la llegada de Kemmerer y su misión en Ecuador (y que influyeron en la permanencia del patrón oro como se detallará más adelante), y la influencia de Estados Unidos en la región, fueron olvidados proyectos y aportes de reforma casi similares a los recomendados por Kemmerer. Paz y Miño (2013) sostiene:

El esquema de organización y funcionamiento del вCE [Banco Central de Ecuador] era parecido al que en 1925 impulsó Luis N. Dillon durante la primera Junta Provisional. Con toda razón Luis N. Dillon expresaría: "Pero el Ecuador es el país de la paradoja [...] Lo que debía secundarse con ardor, como honroso y provechoso para la Patria, se rechazó con indignación, porque eran ecuatorianos los que lo proponían. Este patriotismo al revés no lo hemos comprendido hasta ahora” (p. 67).

Tal como se analizó, las condiciones económicas de Ecuador ya no sólo estaban restringidas por las externas, sino también por las internas. 
Aunque el precio del cacao había aumentado, las plagas habían reducido su producción. A esto se sumaba el déficit del gobierno en 1925 por 5000000 de sucres (véase gráfica 3).

Este proceso deja al descubierto que las limitaciones externas de Ecuador -falta de financiamiento y términos de intercambio en contra- y la restricción interna -falta de producción del principal producto de exportación- llevó a las autoridades ecuatorianas a contratar la asesoría de E. W. Kemmerer y de la misión, con el fin de conseguir el mismo trato que Colombia y Chile para financiar la obra pública que un país subdesarrollado requería. ${ }^{17}$ La misión Kemmerer llega a Guayaquil el 18 de octubre de 1926.

Marchán (1989) afirma que "desafortunadamente, las inversiones que Estados Unidos y otros países realizaban en Sudamérica se paralizaron en 1928, y Ecuador no recibió nada o poco de lo que esperaba" (p. 17) (véase cuadro 3).

A pesar de esto, Drake (1995) en las conclusiones de su estudio sobre la misión Kemmerer expresa que "ilumina sorprendentemente la magnitud de la penetración norteamericana en los Andes en los años veinte" (p. 398). No era tan sólo un asesor monetario de países atrasados, sino un firme defensor de la naciente hegemonía estadunidense, en la que él creía. ${ }^{18}$

En medio de la crisis y del drenaje de reservas oro, Kemmerer (El economista Kemmerer emite varias declaraciones acerca de la seguridad del patrón oro, 6 de noviembre de 1931, El Telégrafo) emitió varias declaraciones acerca de la seguridad del patrón oro del dólar en Estados Unidos, señalando que "es virtualmente irreductible que New York tiene ahora la gran oportunidad de reemplazar a Londres como centro financiero mundial". Esta afirmación se basa en que "Estados Unidos se halla en posesión de la mayor provisión de oro que ningún otro país en el curso de la historia de la humanidad".

Días después de esta declaración, el 13 de noviembre de 1931, el Banco de la Reserva Federal de Nueva York eligió los delegados al Congreso de Banqueros de Lima del 2 de diciembre para la "rehabilitación económica" de Perú, Bolivia, Chile, Colombia y Ecuador: a E. Kemmerer (elegido presidente honorario de la conferencia), a Allan Sproul, ayudante delega-

\footnotetext{
${ }^{17}$ A esto hay que sumar que en 1927 35.5\% del presupuesto del gobierno se destinaba al pago de la deuda pública, que sólo un año antes era de 13.8 por ciento.

${ }^{18}$ Drake (1995), con base en una cadena de evidencias proporcionada por el hijo de E. Kemmerer, Donald L. Kemmerer, y la biblioteca de manuscritos Seely G. Mudd de la Universidad de Princeton, que tenía documentos de las misiones de Kemmerer, entre otras fuentes relevantes, demuestra los nexos entre el departamento de Estado de Estados Unidos, los banqueros estadunidenses y las embajadas estadunidenses en los países andinos. La embajada estadunidense (en cada país andino) era funcional para "facilitar" el trabajo de la misión Kemmerer. La influencia se profundizó a partir de 1929.
} 
do del gobernador del Banco de la Reserva Federal, y a Eric F. Lamb, del departamento extranjero de la misma institución bancaria.

Durante el Congreso de Bancos Centrales en Lima se demostró la fuerte influencia del asesor: "E. W. Kemmerer felicitó muy especialmente a los delegados ecuatorianos señores Enrique Cueva y Esteban F. Carbo, por la firmeza con que el Banco Central del Ecuador había mantenido el talón de oro y por la eficiente propaganda doctrinaria contenida en el boletín mensual de la institución, al que calificó como una de las publicaciones más interesantes entre las de su género" (Mr. Kemmerer felicita a los delegados del Banco Central y les aplaude su energía para conservar el talón de oro, 2 de diciembre 1931, El Telégrafo).

Los delegados ecuatorianos y peruanos se opusieron abiertamente a las medidas de control. La opinión de los delegados ecuatorianos, los señores Cueva y Carbo, tuvo una influencia notable en la conferencia por la experiencia adquirida con la incautación de giros (por parte de Inglaterra con el anuncio de inconvertibilidad), y, además, por la autorizada declaración de Kemmerer de que la dirección del Banco Central del Ecuador había sido muy bien manejada: "Los juicios de nuestros delegados hacen gran peso por la declaración de Kemmerer sobre su acertada política" (Hay ansiedad en Lima por saber los acuerdos de la conferencia de los cinco Bancos Centrales, 9 de diciembre de 1931, El Telégrafo).

En la conferencia de bancos en Lima, entre las catorce cuestiones aprobadas, se recomendó que los gobiernos no debían acudir al Banco Central por préstamos para equilibrar el presupuesto, porque eso generaba inflación. También se recomendó que debía haber una armonía entre la política fiscal y la política bancaria manteniendo la independencia de la banca central (Los despiden ayer de Lima con dos banquetes a los delegados del Banco Central del Ecuador, 9 de diciembre de 1931, El Telégrafo).

Así, los delegados ecuatorianos regresaron más convencidos que nunca de permanecer dentro del bloque del oro, y se mostraron listos para resistir las reformas que el gobierno central quería imponer para aliviar la crisis: "La conferencia ha afirmado la creencia de los países participantes en el patrón oro, a pesar de sus bien conocidos defectos como único standard valor" (Arribaron a New York, 29 de diciembre de 1931, El Telégrafo).

No obstante, las presiones de Kemmerer para que los países andinos se mantuvieran dentro del régimen monetario despertaban sospechas: "El coronel Juan Manuel Lasso manifestó que lo sucedido con Kemmerer fue un plan para que EE.UU. se haga con el oro. Aduce que el sistema de patrón oro está llevando al país a una destrucción" (EE. UU. persigue el acaparamiento del oro mundial, 19 de enero de 1932, El Telégrafo). Tal como Drake (1995, p. 53) afirma, las misiones económicas de Kemmerer hacia los países andinos "probaron ser un método de bajo costo en la ex- 
tensión de la hegemonía norteamericana en el hemisferio", y la mayoría, en 1931, se lanzó contra el gobierno por haberse postrado ante el médico monetario y sus dictámenes.

La presión ideológica de Kemmerer para que Ecuador sostuviera el patrón oro -a pesar de que Gran Bretaña había declarado la inconvertibilidad-, el aumento del tipo de descuento en el Banco de la Reserva Federal de Nueva York de 3.5 a 5\% en el primer semestre de 1928, el acaparamiento de oro por parte de Francia (las reservas de oro se habían triplicado hacia 1930), la concentración de 36\% de las reservas de oro por Estados Unidos en 1931, y en ese mismo año la vertiginosa caída de las reservas de oro ecuatorianas en el segundo semestre, hacen sospechar que la presión ideológica estaba para beneficiar a Estados Unidos; más si Kemmerer creía que Nueva York debería ser el nuevo centro financiero del mundo, y que el patrón oro se sostendría si Estados Unidos no lo abandonaba.

\section{ASPECTOS MACROECONÓMICOS DE LA OBSTINACIÓN MONETARIA}

Samaniego (1988) expresó que la crisis económica y financiera de fines de los años veinte y treinta fue causada por la deficiente estructura económica de Ecuador y no por una crisis monetaria. Si bien es cierto que las características económicas del Ecuador de aquella época llevan a esa conclusión, también es verdad que el régimen monetario establecido en 1927, y no abandonado tempranamente como lo hizo Argentina, agudizó las defectuosas bases de la economía ecuatoriana.

La economía ecuatoriana registró una balanza comercial deficitaria a partir de 1928 (exceptuando 1934), y a la vez la transición como principal producto de exportación del cacao a otros tipos de productos como el café (véase gráfica 4). ${ }^{19}$ La economía enfrentaba el desafío de varios impactos externos e internos que exigían la utilización de todas sus herramientas de política económica.

No obstante, los responsables de la política económica enfrentaron la aguda crisis económica con el mismo instrumento que la fomenta: el mecanismo de ajuste automático proporcionado por el patrón cambio oro. La esperanza en el mecanismo estaba en que la deflación volvía competitiva la economía, sin tomar en cuenta la falta de crédito para las nuevas inversiones destinadas a la exportación y la deflación de orden mundial. Se destaca la resistencia de la economía ecuatoriana y de su régimen monetario

${ }^{19}$ En 1928, el peso de las exportaciones de café y elaborados se encontraba en 17.49\% de los totales. El precio en dólares del quintal de café en 1929 se encontraba en 15.41. Dos años después, estaba por debajo de la mitad (6.71 dólares) (Miño, 1990). 


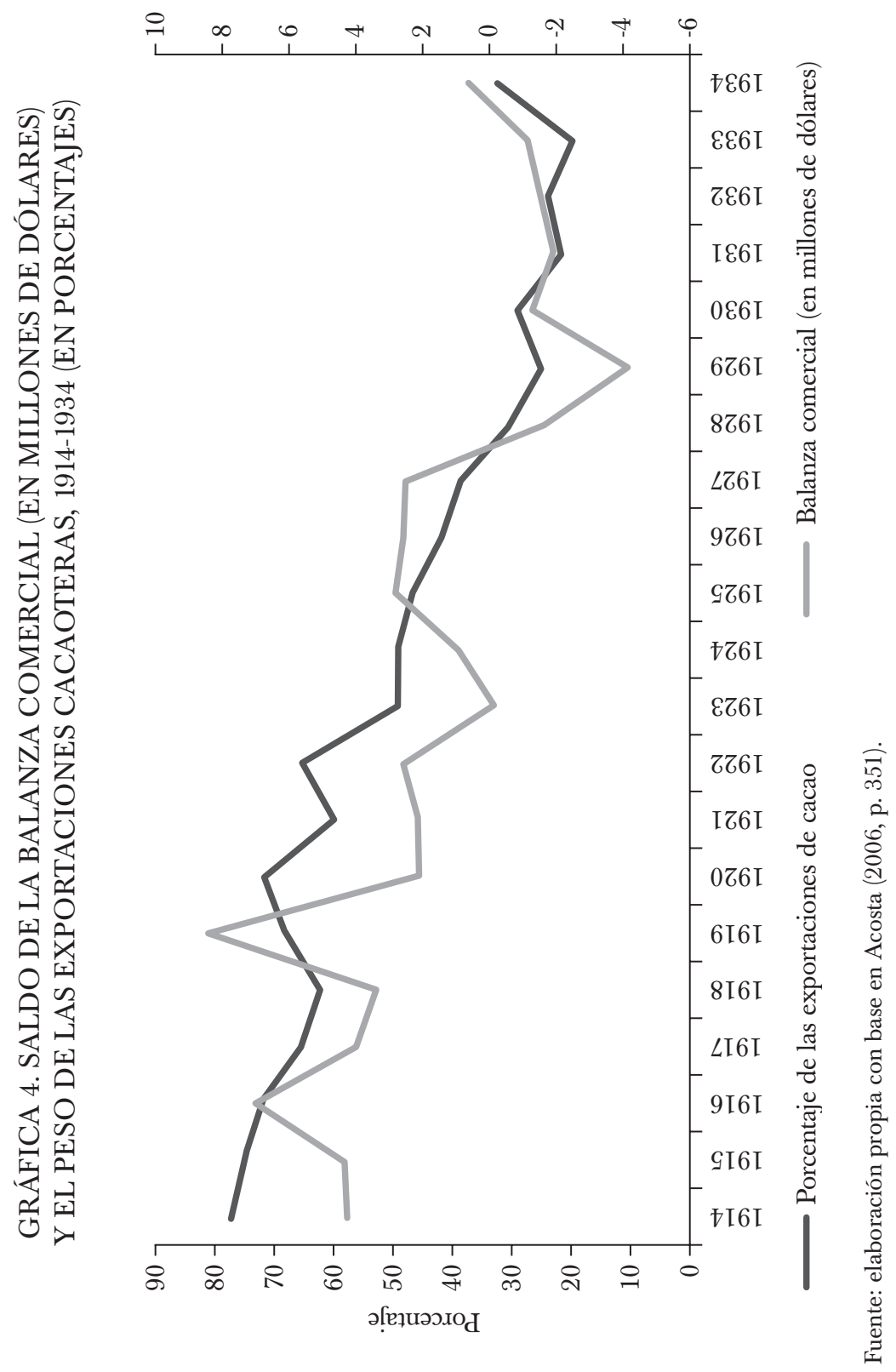


para soportar los impactos mencionados antes y la retroalimentación que se daba de estos.

La resistencia a la crisis (y la confianza irrestricta de Kemmerer en superar la deflación) no sólo era producto de la nueva paridad con la que se instauró el segundo patrón oro, sino también del tipo de producto que vendía Ecuador a los mercados internacionales. Kindleberger (1997, p. 229) afirma que "la lotería de las mercancías trató a los diferentes países de formas distintas". Los países especializados en materias primas y/o alimentos básicos, salvo carburantes, lo pasaron peor que los países especializados en alimentos de semilujos y petróleo (véase cuadro 4).

Con base en esta "lotería de mercancías" Kemmerer había expresado que "el consuelo para el Ecuador es que había países que estaban peor" (Miño, 2008, p. 84). El cuadro 5 ratifica lo señalado por Kindleberger (1997) y la percepción de Kemmerer: la caída del precio de las exportaciones y de los términos de intercambio para Ecuador es menor respecto de las principales economías de Sudamérica. Ecuador pertenecía a los países especializados en alimentos de semilujo con sus exportaciones de cacao, que como lo ratifica Samaniego (1988, p. 67), tuvo una caída mucho menor en sus precios frente a productos como el café, cobre, algodón y caucho.

Además de no establecer el segundo patrón oro con la paridad del primero, y de que la inserción en la división internacional del trabajo -por medio del cacao- le era menos contraproducente a Ecuador que a los demás países de Sudamérica, también se destaca una razón más de las condiciones técnicas y económicas de la dilatada vigencia del patrón oro en este país andino: la falta de protagonismo del canal financiero.

Aunque Ecuador necesitaba de la inversión extranjera directa e indirecta, nunca recibió los flujos de capitales como Argentina, Colombia y Chile. En la balanza de pagos de Ecuador la cuenta capital jamás fue relevante, mientras que la cuenta corriente sí lo fue para el periodo de estudio. En el caso de Argentina, como señala Cortés (2005), la cuenta capital financiaba el déficit de la cuenta corriente (provocado por el desequilibrio de la cuenta de servicios).

No obstante, después del aumento de la tasa de interés estadunidense, los capitales hacia Argentina disminuyeron considerablemente a lo largo de los años de 1928 y 1929, lo que presionó para que este país fuera el primero en abandonar el patrón oro. ${ }^{20}$ Ecuador experimentó desde 1929 una

\footnotetext{
${ }^{20}$ Gerchunoff y Machinea (2015, p. 111) sostienen que "las autoridades argentinas y especialistas estuvieron alertas, o en todo caso algo entrañados en el padecimiento", tal afirmación se debe a la experiencia del ajuste antiinflacionario de 1920-1921 donde se juntaron la fuga de capitales y la caída de los precios internacionales de los alimentos. Para un análisis de la salida del patrón oro (caja de conversión del 25 de agosto de 1927) véanse Rapoport (2008, pp. 144-147) y Paolera y Taylor (2003, pp. 224-227).
} 


\section{CUADRO 4. CUARENTA Y NUEVE PAÍSES EXPORTADORES DE BIENES PRIMARIOS CLASIFICADOS POR PORCENTAJES DE CAÍDAS DE SU EXPORTACIÓN, 1928-1929 HASTA 1932-1933}

\section{Porcentajes de caída}

de la exportación

Más de 80

$75-80$

$70-75$

$65-70$

$60-65$

$55-60$

$50-55$

$45-50$

$30-45$
País

Chile

China

Bolivia, Cuba, Malasia, Perú, El Salvador

Argentina, Canadá, Ceilán, Indias Holandesas, Estonia,

Guatemala, India, Estado Libre de Irlanda, Letonia, México, Siam, España.

Brasil, República Dominicana, Egipto, Grecia, Haití, Hungría, Holanda, Nicaragua, Nigeria, Polonia, Yugoslavia.

Dinamarca, Ecuador, Honduras, Nueva Zelanda.

Australia, Bulgaria, Colombia, Costa Rica, Finlandia, Panamá, Paraguay.

Noruega, Persia, Portugal, Rumania.

Lituania, Filipinas, Turquía, Venezuela.

Fuente: Kindleberger (1997, p. 230).

crisis que se agudizaba pero que jamás fue una masiva fuga de capitales, aunque en el transcurso de dicha crisis los seguía necesitando.

Aunque no se puede construir una serie de tiempo de la inversión extranjera directa e indirecta (o de cartera) por la falta de estadísticas, para 1930 no se registra inversión extranjera indirecta y una cuantía muy pequeña, en comparación con lo recibido por América Latina de inversión extranjera directa (véase cuadro 3). Además, en toda la bibliografía revisada no se destaca que la salida de oro sea por fuga de capitales de las inversiones extranjeras indirectas antes realizadas: la salida de oro se explica por el permanente déficit comercial (véase gráfica 4$){ }^{21}$

${ }^{21}$ Esta afirmación es producto del cálculo siguiente: entre enero de 1928 y diciembre de 1931 las reservas de oro disminuyeron en 36028535 sucres, lo que, al tipo de cambio de cinco sucres por dólar, significa una reducción de 7205707 dólares. Asimismo, el déficit comercial acumulado en ese mismo periodo es de 9064900 dólares. Para una investigación posterior se tendría que revisar cómo se siguió financiando el déficit comercial, puesto que la suspensión del patrón oro en Inglaterra significó la pérdida de 408418 dólares en las reservas de oro. Además, hay que tomar en cuenta la fuga de capitales motivado por la especulación. 
CUADRO 5. ÍNDICES SOBRE LA CONFIRMACIÓN

DE LA HIPÓTESIS DE KINDLEBERGER (1997), AÑO BASE 1970=100 (PRECIOS EN DÓLARES) PAÍSES SELECCIONADOS

\begin{tabular}{lcc}
\hline País & $\begin{array}{c}\text { Precio promedio } \\
\text { de las exportaciones }\end{array}$ & $\begin{array}{c}\text { Relación de precios } \\
\text { del intercambio }\end{array}$ \\
Ecuador & -18.6 & -18.3 \\
Argentina & -41.5 & -31.2 \\
Brasil & -49.1 & -69 \\
Chile & -23.6 & -36.3 \\
México & -15.5 & -41.5 \\
Colombia & -21.9 & -27.1 \\
Perú & -39 & -40 \\
\hline
\end{tabular}

Fuente: elaboración propia con base en Naciones Unidas. Comisión Económica para América Latina y el Caribe (1977).

Por último, a pesar de que el cacao sólo representaba una cuarta parte de las exportaciones totales, ${ }^{22}$ es importante mencionar que en 1929 el precio del cacao había aumentado 87.14\% respecto del precio de 1923 , en promedio. En su punto más bajo, en 1932, el precio del cacao regresó al nivel de 1923 (véase gráfica 3). Esto refuerza la propuesta de Kindleberger $(1997$, p. 229) y la razón de por qué la economía ecuatoriana y el patrón de cambio oro resistieron la crisis que el mismo régimen monetario magnificaba.

\section{LA DEFENSA DOCTRINARIA DE ENRIQUe Cueva, PRESIDENTE DEL BANCO CENTRAL DEL ECUADOR}

Para entender por qué se sostuvo el patrón oro en Ecuador, hay que señalar que Estados Unidos todavía se encontraba bajo este régimen a pesar de que Inglaterra había claudicado en septiembre de 1931. Además, cabe precisar que quien impulsó el restablecimiento del patrón oro en Inglaterra fue Estados Unidos, en virtud de que la ley que había suspendido el patrón oro británico expiraba a finales de 1925 (Eichengreen, 2000, p.

${ }^{22}$ La producción de cacao tuvo una caída de 45\% entre 1923 y 1929. 
84) ${ }^{23}$ Ecuador estaba bajo la influencia de Estados Unidos, y no bajo la de Inglaterra, por medio de la misión Kemmerer. ${ }^{24}$

Sin embargo, la decisión de las autoridades ecuatorianas de permanecer dentro del bloque del oro no era fácil. Para finales de agosto de 1931 el presidente Isidro Ayora renunció en medio de la crisis bancaria, monetaria y social, y las nuevas autoridades se identifican como contrarias a mantener el patrón de cambio oro.

La investigación llevó a examinar la afirmación de Miño (2008, p. 83) sobre la relevancia del nombramiento de Alfredo Baquerizo Moreno como encargado de la presidencia de la república, y de Juan de Dios Martínez Mera como ministro de Hacienda, al ser considerados autoridades menos apegadas al patrón oro $^{25} \mathrm{y}$ vinculadas a sectores económicos de la costa. ${ }^{26}$ Indagar sobre el apoyo o no de las nuevas autoridades encargadas del poder ayudará a esclarecer por qué el patrón oro tuvo vigencia hasta febrero de 1932.

El ministro de Hacienda Martínez expresó enfáticamente, en una entrevista concedida al diario El Telégrafo, que se oponía a la inconvertibilidad y que las ideas del gobierno eran contrarias a ella. Además, afirmó que "todas las medidas que ha propuesto el gobierno se dirigen a la conversión y defensa del talón oro" y que "el ejecutivo procederá con toda decisión en este sentido para que sigan en vigor las disposiciones pertinentes de las leyes bancarias que nos rigen". En esa entrevista también se mencionó el apoyo al Banco Central para que mantenga en todo tiempo la conver-

${ }^{23} \mathrm{El}$ impulso radicaba principalmente en que Estados Unidos no seguiría más tiempo con una política deflacionista para alcanzar el nivel en que se encontraba en 1913, ya que eso perjudicaría a Gran Bretaña que estaba constreñida por la expiración de la ley. Además, ayudó al fluir fondos (reservas de oro) de Nueva York a Londres mediante una reducción del tipo de interés.

${ }^{24}$ Después de la inconvertibilidad de la libra esterlina, el sistema monetario internacional se había dividido en tres bloques: los pocos países que tenían un patrón oro, entre ellos, Estados Unidos; la zona de la libra esterlina, y los países de Europa central y oriental, encabezados por Alemania, en los que existían controles de divisas. Como señala Eichengreen (2000), la depreciación de la moneda de un bloque y el control de cambio en el otro, erosionaron la balanza de pagos de los países que aún tenían un patrón oro.

${ }_{25}$ Aunque Miño (2008, p. 83) más adelante señala que "si bien en un comienzo apoyan al sistema de convertibilidad, no llegan tan lejos en su convencimiento como Enrique Cueva, presidente del Banco Central".

${ }^{26}$ Paz y Miño (2013, p. 21) realiza una periodización que da a conocer la procedencia del nuevo encargado del poder, Eloy Alfaro (1842-1912), quien gobernó el país entre 1895-1901 y 1906-1911 y fue el gran caudillo de la revolución liberal radical. Su asesinato, el 28 de enero de 1912, marcó el fin de esa fase radical. Lo sucedió, por tanto, un liberalismo "moderado", iniciado con el gobierno de Leónidas Plaza (1912-1916) y continuado por un liberalismo francamente "plutocrático", esto es, al servicio de la poderosa banca privada y del alto empresariado de la época, con la sucesión de los presidentes: Alfredo Baquerizo Moreno (1916-1920), José Luis Tamayo (1920-1924) y Luis Cordero (1924-1925). Baquerizo era presidente del Senado cuando le fue encargado el poder el 15 de octubre de 1931. Juan de Dios Martínez Mera se convirtió en presidente constitucional en diciembre de 1932; su periodo culminó en octubre de 1933. 
tibilidad de sus billetes (El gobierno no quiere afectar al talón oro, 12 de noviembre de 1931, El Telégrafo).

No obstante, para los últimos días de enero la situación cambió diametralmente. Tanto el presidente encargado como el ministro de Hacienda buscaron una salida a la crisis que iba en contra del marco legal del patrón oro. La motivación se originaba en que la reserva legal en oro había caído por debajo de $50 \%$ para diciembre de 1931 . La caída de las reservas de oro en diciembre de 1931 fue de 5.73\% respecto del mes anterior, mayor a la registrada en el mes del abandono del patrón oro por Gran Bretaña. En enero se registró una caída de $8.44 \%$ (véase gráfica 5).

El presidente encargado Alfredo Baquerizo M. envió al presidente del Banco Central Enrique Cueva una carta que se hizo pública, donde exponía inquietudes sobre la política monetaria por seguir para solucionar la crisis y encauzar al país por la senda del crecimiento: “¿No sería mejor defender el oro con oro mismo? ¿Restringir su salida, restringiendo su venta o sea concesión de letras? ¿Por qué el banco juzga y aprecia de la operación en billetes para concederla y negarlas, y no de la operación en oro, de la operación en letras, cuando a mi juicio puede y acaso que hacer lo mismo en estas tan dolorosas circunstancias de fuga del oro y restricción del billete, esto es, del circulante?" (El Primer magistrado dirige una carta al presidente del Banco Central, en que juzga la crisis y le sugiere un remedio, 27 de enero de 1932, El Telégrafo).

Desde el Ministerio de Hacienda se comenzaron a demostrar los esfuerzos realizados desde septiembre de 1931, los mismos que ya no alcanzaban para evitar la fuga del oro: "Como ya lo habrá observado usted (director de El Comercio), el pensamiento del Ministerio de Hacienda cristaliza ideas y anhelos que por algún tiempo han flotado en la mente nacional, llegando a concretarse, de un modo u otro, en algunos de los varios proyectos llamados de emergencia que se sometieron al estudio del Congreso de 1931" (Sugerencia del ministro de Hacienda a los banqueros, 30 de enero de 1932, El Telégrafo).

Carta a la que el presidente del Banco Central respondió:

Si de acuerdo con un anterior pensamiento suyo la moneda se considera todavía sana, pero "Todo lo demás se halla enfermo", es natural y lógico que usted se preocupe ahora desde el alto puesto en que está colocado, de arbitrar medios eficaces para evitar el contagio y salvar esa moneda amenazada, afirmando sobre sólidas bases nuestro sistema monetario en vigor [...] prefiero dejar el cargo, a asumir responsabilidades por ir contra la Ley (Don Enrique Cueva dice al Dr. Baquerizo que preferiría dejar el cargo a asumir responsabilidades por ir contra la Ley, 28 de enero de 1932, El Telégrafo). 

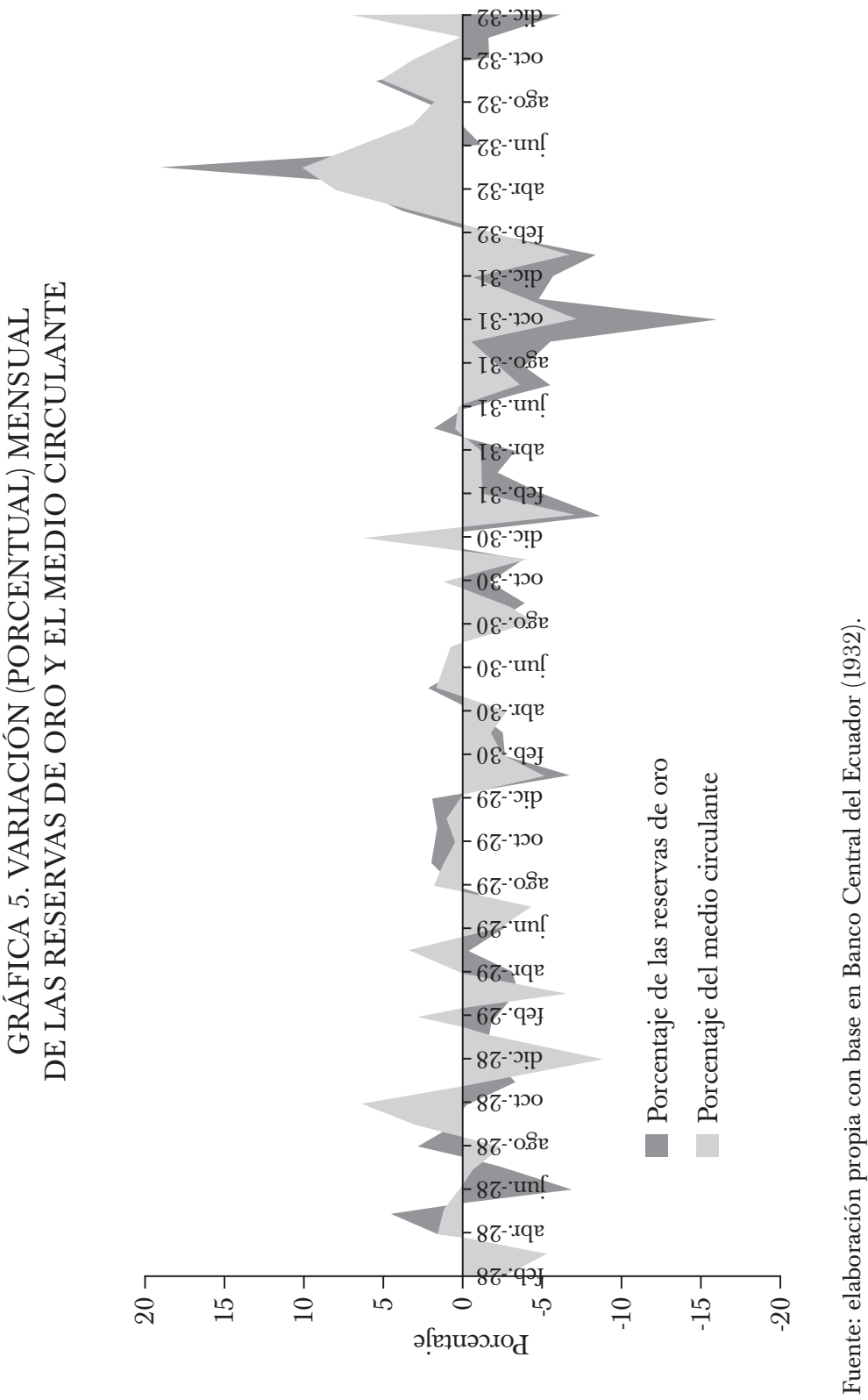
La solución que se entiende era más deflación, ya que, como bien señala Drake (1995), "la única guía de Kemmerer era equilibrar el presupuesto, recortar los gastos domésticos, cumplir con las obligaciones externas, sostener el patrón oro y esperar la recuperación de la economía" (p. 61). El gobierno central, días después de convocar a una conferencia de banqueros privados del país, anuncia la inconvertibilidad de la moneda (Decreto 32) y la obligatoriedad para el Banco Central para otorgar un crédito por 15000000 de sucres (Decreto 33).

La obligatoriedad del crédito hace que Cueva renuncie a su cargo, tal como se lo había señalado al propio presidente Baquerizo. En la carta de Enrique Cueva de renuncia a la presidencia del Banco Central del Ecuador se exponen los siguientes fundamentos en oposición a los decretos de emergencia 32 y 33 (Rodríguez, 1987, pp. 118-121): "Son enteramente opuestos a la autonomía y a las funciones primordiales del Banco Central, y, sobre todo, muy peligrosos para su estabilidad". Señala los intereses detrás del decreto 32: "Una fuerte corriente de opinión sostenida por gremios importantes de las actividades económicas del país, banqueros, miembros del Congreso y del mismo gobierno, la pedían como un calmante para detener la fuga de capitales que generaba la restricción del crédito y consecuentemente la del medio circulante."

Además, consideró el abandono del patrón oro como un "paliativo, pero de ninguna manera, como ustedes comprenderán, el remedio eficaz y permanente que el país necesita para curar los añejos males de su economía”. Según Cueva, las causas del drenaje de reservas de oro estaban en el saldo desfavorable de la balanza de pagos y en la salida de capitales que la desconfianza ha acelerado, señalando que "no correspondía ni le era dable al Banco Central aplicar correctivos eficaces para que esa situación se normalizara".

Si bien es cierto que el presidente del instituto emisor señalaba aquello, expresaba que quien regía la política económica -que no sea lo que le correspondía al Banco Central- debía tomar medidas que se habían establecido en otros países del mundo, quizá medidas tomadas de forma paralela (y contradictorias) al patrón oro. En esa carta de renuncia, Cueva realizó la defensa del Banco Central basado en las causas de la emisión monetaria, con lo que demostraba la endogeneidad del dinero (Rodríguez, 1987, pp. 118-121): "Regido el banco entre nosotros por una ley fundada sobre principios técnicos, su capacidad para aumentar el medio circulante está subordinada a la actividad de los negocios y al volumen de la producción y el ahorro, fuentes genuinas y tal vez únicas de bienestar."

Esta concepción teórica proviene de la escuela clásica, en la cual el dinero no es importante para explicar las fluctuaciones de la economía, ya que la política monetaria responde a cambios en la actividad real, lo que 
se identifica como causación en reversa, y las expectativas de expansiones futuras en el producto llevan a expansiones actuales en la oferta monetaria (Giraldo, 2006, p. 8).

Por lo tanto, la única función del dinero es la de medio de cambio, característica que no afecta al sector real de la economía. Cualquier cambio en la oferta monetaria es producto del ritmo de la actividad económica real y el dinero no es una variable exógena, como se afirma tradicionalmente. En otras palabras, Cueva defendía la neutralidad del dinero en el corto y largo plazos, supuesto del mecanismo de flujo del precio por medio de la teoría cuantitativa del dinero, para corregir los impactos de demanda.

En su carta de renuncia Cueva deja entrever una paradoja que no termina de resolver. Afirma que el patrón oro es el que más confianza inspira y por eso está universalmente aceptado, pero a la vez trata de explicar sus deficiencias en países como Ecuador donde lo considera un caso insólito y absolutamente anormal. No obstante, sobrelleva esta paradoja contrastando la situación económica de ese momento con la que podría ocurrir si se aplicara el decreto de emergencia número 33. En su carta de renuncia expresa:

Si bajo el patrón oro el país ha sufrido las estrecheces del circulante, de que tanto se ha quejado, ahora si se iniciara el régimen de papel inconvertible [...] el país tendría que pasar por angustias mucho mayores, todavía, que aquellas. Con razón se estima por los más reputados economistas a la moneda desquiciada como una calamidad nacional que no perdona a nadie, que requiere remedios largos y penosos y que causa pérdidas irreparables (Rodríguez, 1987, pp. 118-121).

¿Por qué transitar hacia un régimen de papel inconvertible provocaba gran temor para el presidente del Banco Central (y para muchas de las autoridades y actores sociales)? La experiencia desde 1914 hasta 1927 indicaba que la moneda inconvertible al servicio de los bancos privados causaba caos social y político. La llamada guerra bancaria destruía los escuálidos tejidos sociales y productivos del país. Paz y Miño (2005) expresa lo siguiente:

Bancos y banqueros privados dominaban las finanzas nacionales. Ellos fijaban las tasas de interés y el cambio de monedas [...] Fueron acusados de especular con los giros internacionales, de realizar cobros indebidos por sus servicios, de alimentar la economía con sobreemisiones sin respaldo, de ser responsable de la inflación, del abuso con los créditos y del contubernio político con los gobiernos liberales postalfaristas (p. 71).

En esa misma línea, pero más crítico, Acosta (2006) afirma que: 
La libertad cambiaria y financiera que había en el Ecuador de esos años era casi total. El gobierno central dependía de los créditos de las entidades financieras privadas, que a su vez controlaban el poder político. Y la burguesía agroexportadora y financiera, esto es la bancocracia, detentadora de dicho poder político, procuraba readecuar la política económica, buscando moldear la economía según las circunstancias, sin que se afectara el proceso de reproducción del capital; es decir, trasladando las pérdidas hacia las mayorías populares (p. 85).

En el imaginario social de la población y de las autoridades económicas se encontraban las revueltas sociales y las crisis del primer lustro de los años veinte. ${ }^{27}$ Pero sobre todo estaba la característica de la economía ecuatoriana que mencionaba Drake (1995) y que tenía como actores principales a los banqueros de la costa contra los banqueros de la sierra: el regionalismo. ${ }^{28}$

Por último, ¿̇por qué un decreto de emergencia, y no una ley desde el Congreso y del consejo de Estado? Las razones radicaban en que el marco jurídico era de difícil reforma. Drake (1995, p. 272) indica que entre 1929 y 1931 "el Congreso Nacional había tratado de reducir el número de directores del Banco Central, a fin de dar mayor poder a los agricultores y políticos”. Esto significa que en su momento las intenciones de los congresistas no tenían asidero en los representantes de la banca, los que se aferraron al patrón cambio oro hasta que apareció la ley de emergencia económica del 17 de diciembre de 1931. Cuando desapareció el apoyo de la banca, al director del Banco Central no le quedó ningún actor político ni económico a favor.

Esa ley de emergencia, que fue sancionada por el Consejo de Estado, por iniciativa del Ministerio de Hacienda, impedía la partida (fuga) del oro y reglamentó las operaciones bancarias y comerciales. El Consejo de Estado no tomó en cuenta el pedido de los bancos para que sea objetada (El Consejo de Estado sancionó la Ley de Emergencia que regula las inversiones de los bancos y a sus tipos de cambios, 18 de diciembre de 1931, El Telégrafo). ${ }^{29}$

${ }^{27}$ Huelga general y la masacre del 15 de noviembre de 1922, en Guayaquil.

${ }^{28}$ Desde el principio en la obra de Drake (1995) se destaca esta especificidad de Ecuador en comparación con Colombia, Chile, Bolivia y Perú: "Revolución y regionalismo en el Ecuador, 1925-1933".

${ }^{29}$ Este proyecto tenía la oposición de V. E. Estrada, gerente general del Banco La Previsora Banco Nacional de Crédito; de C. J. Arosemena, gerente del Banco de Descuento, y de Augusto Alvarado O., gerente de la Filantrópica, Caja de Préstamos y Depósitos. Los banqueros "consideran que dicha ley de emergencia va a entorpecer la situación económica, pues juzgan el remedio peor que la enfermedad" (El Consejo de Estado sancionó la Ley de Emergencia, 18 de diciembre de 1931, El Telégrafo). 
Como se señaló, en los primeros días del mes de diciembre se celebró la Conferencia de Bancos Centrales en Lima con el objetivo de considerar la rehabilitación económica de Perú, Bolivia, Chile, Colombia y Ecuador, y fijar políticas para reforzar el bloque del oro que ya había abandonado Gran Bretaña. Los delegados de los bancos (centrales) no vieron con buenos ojos la medida que tomó Ecuador por considerarla un paso hacia la adopción de papel moneda (En la conferencia de banqueros de Lima causa mala impresión la ley del Ecuador que dispone el control sobre el cambio, 7 de diciembre de 1931, El Telégrafo).

Por entonces, la conferencia bancaria también declaró como inconveniente el control de cambios por los gobiernos. Insistió en la necesidad de mantener altos tipos de interés para las operaciones mientras continuara la crisis (Técnicamente la conferencia bancaria de Lima ha declarado como inconveniente el control a los cambios por los gobiernos, 9 de diciembre de 1931, El Telégrafo).

Hasta fines de noviembre el sector bancario insistía en no tocar el patrón oro. Las apreciaciones por parte de la banca privada acerca de permanecer dentro del mismo cambiaron semanas después cuando por regulaciones de la ley de emergencia y del propio Banco Central del Ecuador $^{30}$ comenzaron a regularlos y controlarlos en sus operaciones activas y pasivas. ${ }^{31}$ Hay que recordar que los bancos privados conformaban el directorio del Banco Central de esa época, y que su representante era el presidente del directorio.

En la ley de creación del Banco Central del Ecuador el directorio estaba conformado por delegados de la banca privada, del gobierno, de las cámaras de comercio y agricultura, y de los trabajadores. Por la banca privada se encontraba Luis Alberto Carbo y Enrique Cueva. Esta conformación del directorio del Banco Central respondía a la importación de instituciones que aplicaba Kemmerer, tal como Eichengreen (2000, p. 69) señala: "siguiendo el ejemplo de Estados Unidos, que trató de subsanar las deficiencias de su sistema financiero creando el Sistema de la Reserva Federal en 1913, los países de Latinoamérica y de otras regiones establecieron bancos centrales en la década de 1920".

\footnotetext{
${ }^{30}$ Cueva se negó a pagar un giro enviado por el Banco Pichincha a favor del Banco Crédito Agrícola sin justificación alguna. Por lo que los gerentes de los dos bancos privados pretenden retirar su confianza al residente del Banco Central. El presidente del Banco Central contestó lo siguiente: "No he venido al Banco Central a ser instrumento ciego de los bancos económicos" (Hubo un duro choque entre el presidente del Banco Central y los gerentes de los bancos del Pichincha y Crédito Agrícola, 7 de enero de 1932, El Telégrafo).

${ }^{31}$ En respuesta a esta situación, en Quito se inauguró una nueva conferencia de banqueros con autoridades del gobierno nacional para la elaboración de un plan económico (Un vasto plan económico tiene en discusión la conferencia de los banqueros reunida en Quito, 28 de enero de 1932, El Telégrafo).
} 
El problema de la importación de instituciones es que la conformación del directorio albergaba a representantes de la banca privada, actores que habían desencadenado la crisis del primer lustro de los años veinte y que sostuvieron el patrón oro hasta que los dejó de beneficiar. Uno de esos beneficios era la autodepuración del sector: el Banco del Ecuador, uno de los más grandes del sistema, cerró sus puertas en los primeros días de mayo de 1931. En medio de la guerra bancaria, vigente aún en los años del patrón de cambio oro, la banca serrana resultó ganadora, con nuevos banqueros costeños. La autodepuración se profundizó en 1931 (Miño, 2008). ${ }^{32}$

\section{CONCLUSIONES}

El abandono del patrón oro clásico por parte de Ecuador con la ley de moratoria de agosto de 1914 liberó a la banca privada del único medio institucional que la regulaba. No obstante, a partir de esa fecha los banqueros tuvieron los últimos años de bonanza con el producto de exportación que promovía sus actividades financieras: el cacao. El ciclo económico de Ecuador estaba totalmente subordinado al de la economía mundial. A comienzos de la década de 1920, la declinación de las actividades económicas tendría que financiarse con una continua emisión monetaria, que se transformó en inflación y bajos salarios reales. La banca privada se convirtió en el sostén de un modelo agroexportador en crisis. La banca financió al Estado, a comerciantes y a exportadores mediante un elevado costo social.

La revolución juliana, expresión de un proceso social convertido en político, tuvo como objetivo desaparecer el libertinaje de la banca privada. Una vez regulada y controlada se encontró con un Estado que era expresión del atraso económico de Ecuador: carente institucionalización, de organización y de financiamiento. Las autoridades económicas aceptaron que una misión extranjera de una potencia económica en construcción elaborara proyectos de ley para modernizar el Estado, a cambio de obtener financiamiento extranjero.

Se estableció el patrón de cambio oro como una institución que representaba la mayor expresión de orden monetario, pero que, a la vez, ayudaría a mitigar la falta de financiamiento. Este orden monetario se perdió con la ley de moratoria y se restableció con la creación del Banco Central y

\footnotetext{
${ }^{32}$ En la costa, los nuevos bancos, y los más grandes a partir de 1932, fueron: Banco La Previsora y el Banco de Descuento. El gerente del primer banco fue Víctor Emilio Estrada, y del segundo, Carlos Julio Arosemena. En la sierra, destacan en primer lugar Alberto Acosta Soberón, gerente del Banco del Pichincha, y, en segundo lugar, el banquero Humberto Albornoz S., gerente del Banco de Préstamos (Miño, 2008).
} 
con la ley de monedas en 1927, para repeler las malas prácticas financieras y los altísimos costos sociales.

No obstante, el patrón de cambio oro también representaba una camisa de fuerza para corregir las ondas deflacionarias de la economía mundial. En Argentina, tenían muy claro que este régimen monetario sólo funcionaba en momentos de auge. Para el joven Raúl Prebisch esta crisis representaba la repetición de un viejo fenómeno y que el régimen era en extremo inadecuado (Rapoport, 2008). Ecuador insistió en no salir del bloque del oro y siguió al pie de la letra las asesorías del presidente de la misión de expertos extranjeros, Edwin Kemmerer.

Las asesorías se fundamentaban en los beneficios del mecanismo de ajuste automático que llevaría a la economía por la senda de la recuperación y el crecimiento. Esa insistencia también se sostenía por la caída de los términos de intercambio de Ecuador en comparación con los otros países de Sudamérica, y en la forma como se instauró el patrón de cambio oro.

Mientras duró la obstinación monetaria, se consolidó un proceso de autodepuración del sistema bancario. Cuando este proceso tomó forma, el sector bancario entró en crisis y uno de los dos mayores bancos de la época quebró: el Banco del Ecuador. Varios bancos pequeños lo siguieron. Los bancos que soportaron la crisis pasaron a tomar posiciones dentro del directorio del Banco Central, su mayor exponente fue el gerente del Banco La Previsora, Víctor Emilio Estrada. Cuando el poder político les impuso regulaciones y controles a los banqueros a finales de 1931 con el fin de motivar la recuperación de la economía, simplemente la banca privada no apoyó más el seguir sosteniendo el patrón de cambio oro.

A lo largo de 1931 hasta el 8 de febrero de 1932 -mientras el país perdía cuantiosas reservas de oro y la crisis se profundizaba hasta poner en contradicción los intereses de los sectores económicos-, banqueros, políticos y la sociedad en su conjunto se alejaron de esta obstinación monetaria dejando solo al presidente del Banco Central, que lo único que tenía como sustento era la influencia de Kemmerer.

\section{LISTA DE REFERENCIAS}

Acosta, A. (2006). Breve historia económica del Ecuador. Quito: Corporación Editora Nacional.

Arosemena, G. (1990). Ecuador: evolución y búsqueda del despegue económico 1830-1938.

Guayaquil: Centro de Investigación y Cultura/Banco Central del Ecuador. Arosemena, G. (1998). La historia empresarial del Ecuador. Guayaquil: Autor. 
AyAla, E. (1988). De la revolución alfarista al régimen oligárquico liberal (1895-1925). En E. Ayala (ed.), Nueva historia del Ecuador (pp. 121-166). Quito: Corporación Editora Nacional/Grijalbo.

BAnco Central del ECUADOr [BCE] (1932). Quinto informe anual que el presidente del Banco presenta a los accionistas y a la superintendencia bancaria por el ejercicio económico del año de 1932. Quito: Autor.

Bértola, L. y OcAmpo, J. A. (2010). Desarrollo, vaivenes y desigualdad: una historia económica de América Latina desde la independencia. Madrid: Secretaría General Iberoamericana.

CArbo, L. A. (1978). Historia monetaria y cambiaria del Ecuador. Desde la época colonial. Quito: Banco Central del Ecuador.

Chiriboga, M. (2013). Jornaleros, grandes propietarios, y exportación cacaotera 1790-1925. Quito: Corporación Editora Nacional.

CORTÉs, R. (2005). La economía política de la Argentina en el siglo XX. Buenos Aires: Edhasa.

Cueva, A. (2007). El desarrollo del capitalismo en América Latina. México: Siglo XXI Editores.

Drake, P. (1995). Kemmerer en los Andes. Quito: Banco Central del Ecuador.

Eichengreen, B. (2000). La globalización del capital. Historia del sistema monetario. Barcelona: Antoni Bosch Editor.

García, U. (2014). Control de cambios y el sistema de cambios múltiples en Uruguay: 19311959. Uruguay: Universidad de la República (Serie Documentos de Trabajo, DT18/2014).

Gerchunoff, P. y Machinea, J. L. (2015). Circulando en el laberinto: la economía política de la salida del patrón oro en la Argentina (1929-1933). Revista CEPAL, 117, 109-126. Recuperado de http://repositorio.cepal.org/handle/11362/39470

Giraldo, A. F. (2006). La neutralidad del dinero y la dicotomía clásica en la macroeconomía. Cuadernos de Economía, 25(45), 75-93. Recuperado de http://www.redalyc. org/articulo.oa?id=282121957004

Hollihan, M. (1989). El medio circulante y la economía ecuatoriana en los años treinta. Revista Ecuatoriana de Historia Económica, 3(6), 15-86.

Kindleberger, CH. (1997). La crisis económica 1929-1939. Barcelona: Folio.

MARChÁN, C. (1989). La crisis deflacionaria de la economía ecuatoriana de los años treinta. Revista Ecuatoriana de Historia Económica, 3(6), 103-163.

MARICHAL, C. (2013). Nueva historia de las grandes crisis financieras: una perspectiva global, 1873-2008. México: Debate.

MiÑo, W. (1990). La economía ecuatoriana de la gran recesión a la crisis bananera (pp. 37-69). En E. Ayala (ed.), Nueva historia del Ecuador. Quito: Corporación Editora Nacional/Grijalbo.

Miño, W. (2008). Breve historia bancaria del Ecuador. Quito: Corporación Editora Nacional. 
MÖRnER, M. (1989). La evolución del mercado mundial y su relación con el cambio de la economía andina (1890-1950): estudio comparativo de Bolivia, Ecuador Perú. Revista Ecuatoriana de Historia Económica, 5, 13-78.

NACIONEs UnidAs. COMisión ECONÓMICA PARA AmÉRICA LATINA Y El CARIBE [CEPAL] (1977). América Latina relación de precio del intercambio. Santiago: Autor. Recuperado de http://repositorio.cepal.org/handle/11362/32799

Naranjo, M. (2017). Sombras en la política económica de los gobiernos julianos. Quito: Pontificia Universidad Católica de Quito (inédito).

Oleas, J. (1995). La política económica del Banco Central del Ecuador: Ciclos recesivo y expansivo de política monetaria y control del tipo de cambio: 1927-1937 (Tesis de maestría). Quito: Facultad Latinoamericana de Ciencias Sociales.

PaOlera, G. y TAYlor, A. (2003). Tensando el ancla. La caja de conversión argentina y la búsqueda de la estabilidad macroeconómica 1880-1935. Buenos Aires: Fondo de Cultura Económica.

PAZ Y MiÑo, J. (1997). La polémica sobre la inconvertibilidad monetaria de 1914. Revista Gestión Economía y Sociedad, 32, 54-55.

PAZ Y MiÑo, J. (2005). La controversia entre "banqueros" y "sectores productivos" tiene historia. Revista Gestión Economía y Sociedad, 137, 71-72.

PAZ Y MiÑo, J. (2013). La revolución juliana en Ecuador (1925-1931): políticas económicas. Quito: Ministerio Coordinador de Política Económica.

PREBisch, R. (1995). El patrón oro y la vulnerabilidad económica de nuestros países. Revista Ecuatoriana de Historia Económica, 5(10), 112-138.

Rapoport, M. (2008). Histórica económica, política y social de la Argentina (1880-2003). Buenos Aires: Emecé.

Rodríguez, F. (est. intr. y doc.)(1987). Debates sobre la inconvertibilidad del sucre en el Directorio del Banco Central en 1932. Estudio Introductorio y Documento. Revista Ecuatoriana de Historia Económica, 1(1), 99-166.

Samaniego, J. (1988). Crisis económica del Ecuador. Quito: Banco Central del Ecuador.

Turrent, E. (2015). Las reformas monetarias de 1931 y 1932 en México: críticas e incomprensión. América Latina en la Historia Económica, 22(2), 50-70. DOI: 10.18232/ alhe.v22i2.589

\section{ARCHIVOS}

AHG Archivo Histórico del Guayas, Guayaquil, Ecuador.

BCE Biblioteca de la Sucursal Mayor del Banco Central del Ecuador, Guayaquil, Ecuador.

BMG Hemeroteca de la Biblioteca Municipal de Guayaquil.

ANH Academia Nacional de Historia, Quito, Ecuador. 